\title{
Recent development of $\mathrm{A}_{2} \mathrm{~B}_{2} \mathrm{O}_{7}$ system transparent ceramics
}

\author{
Zhengjuan WANG ${ }^{a, b,{ }^{*}}$, Guohong ZHOU ${ }^{a, b,{ }^{*}}$, Danyu $\mathrm{JIANG}^{a}$, Shiwei WANG ${ }^{a, b,{ }^{*}}$ \\ ${ }^{a}$ State Key Laboratory of High Performance Ceramics and Superfine Microstructure, Shanghai \\ Institute of Ceramics, Chinese Academy of Sciences, Shanghai 200050, China \\ ${ }^{b}$ Key Laboratory of Transparent Opto-functional Inorganic Materials, Shanghai Institute of Ceramics, \\ Chinese Academy of Sciences, Shanghai 200050, China \\ Received: June 11, 2018; Accepted: June 19, 2018 \\ (C) The Author(s) 2018. This article is published with open access at Springerlink.com
}

\begin{abstract}
A}_{2} \mathrm{~B}_{2} \mathrm{O}_{7}$ system compounds, which usually present three phase structures mainly based on the ionic radius ratios of $r_{\mathrm{A}}$ and $r_{\mathrm{B}}\left(r_{\mathrm{A}} / r_{\mathrm{B}}\right)$, have been studied for potential applications in many fields, such as thermal barrier coatings, luminescence powders, fast-ion conductors, photocatalysts, and matrices for immobilization of highly active radionuclides. Since $2005, \mathrm{La}_{2} \mathrm{Hf}_{2} \mathrm{O}_{7}$ was fabricated into transparent ceramics and much more attentions were paid on $\mathrm{A}_{2} \mathrm{~B}_{2} \mathrm{O}_{7}$ transparent ceramics for new applications. In this review, the development of $\mathrm{A}_{2} \mathrm{~B}_{2} \mathrm{O}_{7}$ system transparent ceramics was described. The structure characteristics, powder synthesis method, and sintering techniques of the final $\mathrm{A}_{2} \mathrm{~B}_{2} \mathrm{O}_{7}$ transparent ceramics were summarized. After that, the mostly reported $\mathrm{A}_{2} \mathrm{Hf}_{2} \mathrm{O}_{7}, \mathrm{~A}_{2} \mathrm{Zr}_{2} \mathrm{O}_{7}$, and $\mathrm{A}_{2} \mathrm{Ti}_{2} \mathrm{O}_{7}$ system transparent ceramics were systematically introduced. The potential application fields and future development trends were also discussed, focusing on scintillators, optical elements, and other luminescent materials.
\end{abstract}

Keywords: $\mathrm{A}_{2} \mathrm{~B}_{2} \mathrm{O}_{7}$ system transparent ceramics; powder synthesis; sintering; potential applications

\section{Introduction}

Since the 1950s, the first translucent $\mathrm{Al}_{2} \mathrm{O}_{3}$ was reported [1], and many transparent ceramics were developed, including oxide/non-oxide transparent ceramics, such as $\mathrm{MgO}$ [2], $\mathrm{Y}_{2} \mathrm{O}_{3}$ [3], $\mathrm{CaO}$ [4], $\mathrm{BeO}$ [5], $\mathrm{ZrO}_{2}$ [6], $\mathrm{MgAl}_{2} \mathrm{O}_{4}$ [7], $\mathrm{LiAl}_{5} \mathrm{O}_{8}$ [8], $\mathrm{Gd}_{2} \mathrm{O}_{3}$ [9], $\mathrm{Lu}_{2} \mathrm{O}_{3}$ [10,11], $\mathrm{Y}_{3} \mathrm{Al}_{5} \mathrm{O}_{12}$ [12,13], PLZT $\left(\mathrm{Pb}_{1-x} \mathrm{La}_{x}\left(\mathrm{Zr}_{y} \mathrm{Ti}_{z}\right) \mathrm{O}_{3}\right)$ [14], (Y,Gd) $)_{2} \mathrm{O}_{3}: \mathrm{Eu}[15,16], \mathrm{Gd}_{2} \mathrm{O}_{2} \mathrm{~S}: \operatorname{Pr}[17,18], \mathrm{Gd}_{3} \mathrm{Ga}_{5} \mathrm{O}_{12}$ : $\mathrm{Cr}$,Ce [19], and $\mathrm{CaF}_{2}$ [20], $\mathrm{MgF}_{2}$ [21], $\mathrm{SrF}_{2}$ [22], $\mathrm{BaF}_{2}$ [23], AlN [24], AlON [25,26], SiAlON [27], ZnS [28],

* Corresponding authors.

E-mail: Z. Wang,wzhj926@mail.sic.ac.cn;

G. Zhou, sic_zhough@mail.sic.ac.cn;

S.Wang, swwang51@mail.sic.ac.cn
ZnSe [29], CdTe [30], etc. They have been used or have potential applications in many fields, such as high pressure sodium lamp, ceramic metal halide lamp, filament of LED, high refractive index camera lens, bulletproof windows, or missile radome. Some of them possess opto-functional properties after doping with rare earth elements and can be used as laser media and scintillator in X-CT or PET.

$\mathrm{A}_{2} \mathrm{~B}_{2} \mathrm{O}_{7}$ system materials have been studied as early as in the 1960s [31], but they were used as thermal barrier coatings [32], luminescence powders [33,34], fast-ion conductors [35,36], photocatalysts [37], matrices for immobilization of highly active radionuclides [38-40], and so on, while the study on $\mathrm{A}_{2} \mathrm{~B}_{2} \mathrm{O}_{7}$ system transparent ceramics was kicked off in the 2000s. Their mainly potential applications are scintillator hosts as most of 
them have high density and effective atomic number, which would gain higher X-ray or $\gamma$-ray stopping power. Then, many transparent ceramics with the composition of $\mathrm{A}_{2} \mathrm{~B}_{2} \mathrm{O}_{7}$ were fabricated in recent years, such as $\mathrm{La}_{2} \mathrm{Hf}_{2} \mathrm{O}_{7}[41,42], \quad \mathrm{La}_{2-x} \mathrm{Gd}_{x} \mathrm{Hf}_{2} \mathrm{O}_{7} \quad[43,44]$, $\mathrm{La}_{2} \mathrm{Zr}_{2} \mathrm{O}_{7}$ [45], $\mathrm{Nd}_{2} \mathrm{Zr}_{2} \mathrm{O}_{7}$ [46], $\mathrm{La}_{2-x} \mathrm{Gd}_{x} \mathrm{Zr}_{2} \mathrm{O}_{7}$ [47,48], $\mathrm{La}_{2-x} \mathrm{Lu}_{x} \mathrm{Zr}_{2} \mathrm{O}_{7}$ [49], and $\mathrm{Lu}_{2} \mathrm{Ti}_{2} \mathrm{O}_{7}$ [50]. Also, rare earth ion doped $\mathrm{A}_{2} \mathrm{~B}_{2} \mathrm{O}_{7}$ system transparent ceramics [42,5154] were fabricated to study their luminescent properties.

In this review, the structure characteristics, powder synthesis and ceramic sintering method, and potential applications of $\mathrm{A}_{2} \mathrm{~B}_{2} \mathrm{O}_{7}$ system transparent ceramics were systematically introduced. Finally, the development trends were described.

\section{Structure characteristics}

The crystal structure of $\mathrm{A}_{2} \mathrm{~B}_{2} \mathrm{O}_{7}$ compounds depends on ionic radius ratio of $r_{\mathrm{A}}$ and $r_{\mathrm{B}}\left(r_{\mathrm{A}} / r_{\mathrm{B}}\right)$, temperature, and pressure. The most commonly seen structures are cubic pyrochlore and defective fluorite phases, and sometimes monoclinic phase exists. In general, $r_{\mathrm{A}} / r_{\mathrm{B}}$ is the most important factor. According to Subramanian et al. [55], pyrochlore structure steadily exists when $r_{\mathrm{A}} / r_{\mathrm{B}}=1.46-1.78$, where $\mathrm{A}$ and $\mathrm{B}$ ions are distributed in order. Anion-deficient fluorite is the stable structure when $r_{\mathrm{A}} / r_{\mathrm{B}}<1.46$, and the arrangement of $\mathrm{A}$ and $\mathrm{B}$ ions is disordered, while the monoclinic structure is stable when $r_{\mathrm{A}} / r_{\mathrm{B}}>1.78$.

Figure 1 shows the crystal structure diagram of pyrochlore and defective fluorite [56]. Ideal pyrochlore structure is a super structure derivative of the simple fluorite structure $\left(\mathrm{AO}_{2}\right)$, where $\mathrm{A}$ and $\mathrm{B}$ cations are ordered along the $\langle 110\rangle$ direction and one-eighth of the oxygen ions are absent. It can be written as $\mathrm{A}_{2} \mathrm{~B}_{2} \mathrm{O}_{6} \mathrm{O}^{\prime}$ and belongs to the space group $F d \overline{3} m(Z=$ 8 ). The A, B, O, $\mathrm{O}^{\prime}$ ions occupy $16 \mathrm{c}, 16 \mathrm{~d}, 48 \mathrm{f}$, and $8 \mathrm{~b}$ four crystalline sites, respectively. The unoccupied $8 \mathrm{a}$ site corresponds to the oxygen vacancy. As the oxygen vacancy resides in the tetrahedral interstitial site between adjacent B-site cations which reduces the coordination number of $\mathrm{B}$ cation from 8 to 6 , while the coordination number of A cation is still 8 [40,57-59]. The defective fluorite structure exhibits the $F m \overline{3} m$ $(Z=1)$ space group, and the arrangement of the cations and the distribution of the oxygen vacancies become disordered. In XRD patterns, the existence of diffraction peaks corresponding to (331) and (511) reflections is

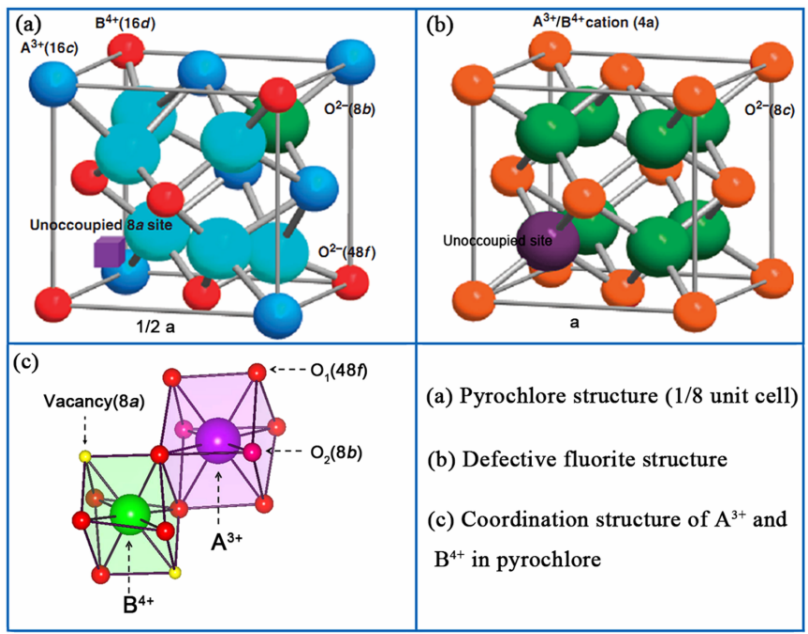

Fig. 1 Crystal structures of pyrochlore and defective fluorite: (a) one-eighth of unit cell of pyrochlore structure; (b) defective fluorite structure; (c) coordination structure of $\mathrm{A}^{3+}$ and $\mathrm{B}^{4+}$ in pyrochlore. Reproduced with permission from Ref. [56], (C) University of Chinese Academy of Sciences 2015.

always considered as a characteristic of the pyrochlore structure, which is a mark to be used to distinguish pyrochlore from defective fluorite structure. However, these characteristic peaks are intrinsically of low intensity [33].

\section{Synthesis methods of $A_{2} B_{2} O_{7}$ powders}

To date, the reported $\mathrm{A}_{2} \mathrm{~B}_{2} \mathrm{O}_{7}$ system transparent ceramics mainly include the compounds with $\mathrm{A}=\mathrm{La}$, $\mathrm{Gd}, \mathrm{Yb}, \mathrm{Lu}, \mathrm{Y}$, and B = Hf, Zr, Ti, Sn [60]. Most of the studies were in experimental stage, and focused on powder synthesis and ceramic sintering. There are many methods that have been used to synthesize $\mathrm{A}_{2} \mathrm{~B}_{2} \mathrm{O}_{7}$ powders, like the solid state method, hydrothermal process and solvothermal synthesis, molten salt synthesis, co-precipitation method, sol-gel process (including the stearic acid method and Pechini method), and combustion method. The progress of powder synthesis of $\mathrm{A}_{2} \mathrm{~B}_{2} \mathrm{O}_{7}$ system transparent ceramics is summarized in this part.

\section{1 Solid state method}

Solid state method is a conventional method for preparation of oxide powders; it is simple and applicable for many compounds including simple and complex compounds.

In 2006, a series of compositions with the general formula $\mathrm{RE}_{2} \mathrm{Hf}_{2} \mathrm{O}_{7}(\mathrm{RE}=\mathrm{Dy}, \mathrm{Ho}, \mathrm{Er}, \mathrm{Tm}, \mathrm{Lu}, \mathrm{Y})$ were prepared by a standard solid state route and characterized 
by powder XRD and Raman spectroscopy [61]. AR grade $\mathrm{RE}_{2} \mathrm{O}_{3}(\mathrm{RE}=\mathrm{La}, \mathrm{Nd}, \mathrm{Sm}, \mathrm{Dy}, \mathrm{Ho}, \mathrm{Er}, \mathrm{Tm}, \mathrm{Lu}, \mathrm{Y})$ and $\mathrm{HfO}_{2}$ were first heated at $900{ }^{\circ} \mathrm{C}$ overnight to remove moisture and other volatile impurities. Then stoichiometric amounts of the reactants were weighed and mixed to get the compositions corresponding to $\mathrm{RE}_{2} \mathrm{Hf}_{2} \mathrm{O}_{7}$. And the mixtures were subjected to a three-step heating protocol $\left(1200{ }^{\circ} \mathrm{C} 36 \mathrm{~h}-1300{ }^{\circ} \mathrm{C}\right.$ $36 \mathrm{~h}-1400{ }^{\circ} \mathrm{C} 48 \mathrm{~h}$ ) as followed with intermittent grindings. Subsequently, one more heat treatment at $1700{ }^{\circ} \mathrm{C}$ for $6 \mathrm{~h}$ was given to each sample to investigate the existence of pyrochlore structure. The Raman and XRD results showed that $\mathrm{RE}_{2} \mathrm{Hf}_{2} \mathrm{O}_{7}(\mathrm{RE}=$ $\mathrm{La}, \mathrm{Nd}, \mathrm{Sm}$ ) crystallized in fully ordered pyrochlore phase, while $\mathrm{RE}_{2} \mathrm{Hf}_{2} \mathrm{O}_{7}(\mathrm{RE}=\mathrm{Ho}, \mathrm{Er}, \mathrm{Tm}, \mathrm{Lu}, \mathrm{Y})$ were unequivocally defect-fluorites. In the case of $\mathrm{Dy}_{2} \mathrm{Hf}_{2} \mathrm{O}_{7}$, there was competition between defect-fluorite and pyrochlore lattices. This conventional solid state synthesis method involves many cycles of grinding of the component oxides and heating at high temperatures, and usually yields inhomogeneous complex oxides. Thus, some researchers developed a mechano-chemical synthesis method, which was a modified solid state reaction method, and usually long time ball milling was required to obtain single phase compounds. In 2005, $\mathrm{A}_{2}\left(\mathrm{Ti}_{(1-y)} \mathrm{Zr}_{y}\right)_{2} \mathrm{O}_{7}\left(\mathrm{~A}=\mathrm{Gd}^{3+}, \mathrm{Y}^{3+}\right)$ powders with pyrochlore structure were obtained by this mechanochemical synthesis method [62]. Stoichiometric mixtures of the constituent oxides were milled in a planetary ball mill with a speed of $350 \mathrm{rpm}$. XRD results showed that chemical changes occurred in the powder mixtures after milling for $19 \mathrm{~h}$, and single phase solid solutions were obtained. The powders were examined by SEM and found that they were basically consisted of submicronsized agglomerates and aggregates of nanoparticles. As this method did not require post calcination process, it was relatively simpler than the traditional solid state reaction and the powders obtained were much finer. In 2006, $\mathrm{Gd}_{2}\left(\mathrm{Sn}_{1-y} \mathrm{Zr}_{y}\right)_{2} \mathrm{O}_{7}$ solid solutions with pyrochlore structure were also synthesized by this method [63]. XRD patterns showed the milled samples were similar to that of an anion deficient fluorite or to that of highly disordered pyrochlore but with weak superstructure reflections. All the samples became pyrochlore structure when calcined at $1450{ }^{\circ} \mathrm{C}$. That is to say, to obtain powders with high crystallinity, high temperature calcination is still required.

As solid state method usually needs long synthesis time and higher temperature, and the synthesized powders have wide particle size distribution and large particle size with low sintering activity, researchers have moved to wet chemical synthesis routes in order to prepare pure and homogeneous $\mathrm{A}_{2} \mathrm{~B}_{2} \mathrm{O}_{7}$ powders. In this case, powders at submicron or even nanometer scales can be obtained with significantly improved sintering activity.

\section{2 Hydrothermal method and solvothermal synthesis}

Hydrothermal synthesis has been used to produce ceramic nanopowders with high crystallinity, high chemical homogeneity, and more stoichiometric. To date, $\mathrm{Ln}_{2} \mathrm{Sn}_{2} \mathrm{O}_{7}$ ( $\left.\mathrm{Ln}=\mathrm{La}, \mathrm{Y}, \mathrm{Lu}, \mathrm{Gd}\right)$ nanocrystals [64] and $\mathrm{Y}_{2} \mathrm{Zr}_{2} \mathrm{O}_{7}: \mathrm{Tb}^{3+}$ powders [65] were prepared by this method. Take $\mathrm{Y}_{2} \mathrm{Sn}_{2} \mathrm{O}_{7}: \mathrm{Yb}^{3+}$ as an example to illustrate the detailed hydrothermal synthesis procedure. First, yttrium nitrate salt was dissolved in distilled water to form $0.1 \mathrm{mmol} / \mathrm{L}$ solution. Then certain amount of $\mathrm{Yb}\left(\mathrm{NO}_{3}\right)_{3}$ was added into the above solution under magnetic stirring condition. Keep the stirring for several minutes until the solution turned to uniformity, then $0.1 \mathrm{mmol} / \mathrm{L}$ sodium stannate was added into the solution and white precipitate was formed. The above solution was transferred into a Teflon-lined stainless steel autoclave and heated at $180{ }^{\circ} \mathrm{C}$ for $18 \mathrm{~h}$, and naturally cooled to room temperature. The product was collected by centrifugation, washed with distilled water and alcohol for several times, and dried at $60{ }^{\circ} \mathrm{C}$ for $24 \mathrm{~h}$ in air. XRD patterns showed that all the obtained powders had cubic pyrochlore structure.

Also, solvothermal synthesis of $\mathrm{Y}_{2} \mathrm{Ti}_{2} \mathrm{O}_{7}: \mathrm{Eu}^{3+}$ sphere powders was reported by Pavitra et al. [66] in 2013. Organic solvent (2-propanol) was chosen as the solvent instead of water. Yttrium nitrate, titanium isopropoxide, and europium nitrate were the raw materials. The specific synthesis process was similar to the hydrothermal method.

The above experiments showed that hydrothermal method and solvothermal synthesis are energy conservative methods to obtain $\mathrm{A}_{2} \mathrm{~B}_{2} \mathrm{O}_{7}$ powders with pure phase composition at low temperature. Besides, the phase composition, particle size, and morphology, etc., can be controlled by adjusting the precursor concentration, reaction temperature and pressure, holding time, and additives.

\section{3 Molten salt synthesis method}

The molten salt synthesis (MSS) is intrinsic simple, versatile, and cost-effective. It can be used to prepare 
chemically purified, single phase powders at lower temperature and often in overall shorter reaction time with little residual impurities as compared with conventional solid state reactions. Thus, it was attractive by many researchers to prepare a wide range of complex oxide nanocrystals [67]. Usually, one salt (e.g., $\mathrm{NaCl}$ ) or a eutectic mixture of salts (e.g., $\mathrm{NaCl} / \mathrm{KCl} ; \mathrm{NaNO}_{3}$ / $\mathrm{KNO}_{3}$ ) is chosen as the molten salt medium. In 2009, Mao et al. [68] prepared nanocrystals with $\mathrm{A}_{2} \mathrm{~B}_{2} \mathrm{O}_{7}$ $(\mathrm{A}=\mathrm{La}, \mathrm{Er}$, or their mixture; $\mathrm{B}=\mathrm{Zr}$, Hf, or their mixture) composition by this method. First, a single-source complex precursor $\mathrm{A}(\mathrm{OH})_{3} \cdot \mathrm{BO}(\mathrm{OH})_{2} \cdot \mathrm{nH}_{2} \mathrm{O}$ was prepared via co-precipitation of $\mathrm{A}\left(\mathrm{NO}_{3}\right)_{3}$ and $\mathrm{BO}\left(\mathrm{NO}_{3}\right)_{2} / \mathrm{BOCl}_{2}$ in a dilute ammonia solution at room temperature. The precursor complex was then purified by filtration and washing with water. After being air-dried for $24 \mathrm{~h}$, the complex precursor was mixed with nitrate mixture $\left(\mathrm{NaNO}_{3}: \mathrm{KNO}_{3}=1: 1\right)$. The mixture was transferred into a covered nickel crucible and heated to $650{ }^{\circ} \mathrm{C}$ at $10{ }^{\circ} \mathrm{C} / \mathrm{min}$ and then isothermally annealed at $650{ }^{\circ} \mathrm{C}$ for $6 \mathrm{~h}$. After being cooled to room temperature, the resulting product was centrifuged and purified with deionized water several times. After drying, $\mathrm{A}_{2} \mathrm{~B}_{2} \mathrm{O}_{7}$ nanocrystals were obtained.

In this method, the precursor molecules disperse, dissociate, rearrange, and then diffuse rapidly throughout the salt medium at high temperature. The desired oxide phase is formed through an initial nucleation step followed by a growth process. Thus, relatively homogeneous powders can be obtained.

\section{4 Co-precipitation method}

Co-precipitation method is a simple, inexpensive, and quick way to synthesize various oxide powders. Usually, chloride, nitrate, or oxychloride, etc., were used as the initial reactants, and ammonia, ammonium bicarbonate, or oxalate were used as the precipitant. Typically, precipitates are prepared and then the target oxide products are obtained by a subsequent calcination process. In previous works, $\mathrm{Ln}_{2} \mathrm{Ti}_{2} \mathrm{O}_{7}(\mathrm{Ln}=\mathrm{Lu}, \mathrm{Gd}, \mathrm{Yb}$, Tm) [69,70], $\left(\mathrm{La}_{x} \mathrm{Gd}_{1-x}\right)_{2} \mathrm{Zr}_{2} \mathrm{O}_{7}$ [71], $\left(\mathrm{Nd}_{x} \mathrm{Gd}_{1-x}\right)_{2} \mathrm{Zr}_{2} \mathrm{O}_{7}$ [72], $\mathrm{Y}_{2} \mathrm{Hf}_{2} \mathrm{O}_{7}$ [73], and $\mathrm{Gd}_{2} \mathrm{Hf}_{2} \mathrm{O}_{7}: \mathrm{Ce}$ [74] powders were prepared by co-precipitation method. The morphology of the ceramic powders can be modified by adding surfactant [73]. Zhou et al. [73] prepared $\mathrm{Y}_{2} \mathrm{Hf}_{2} \mathrm{O}_{7}$ powders by oxalate co-precipitation method, and different shapes such as platelet, rod, and spherical shape were obtained by controlling the concentration of the surfactant PEG6000 (Fig. 2).
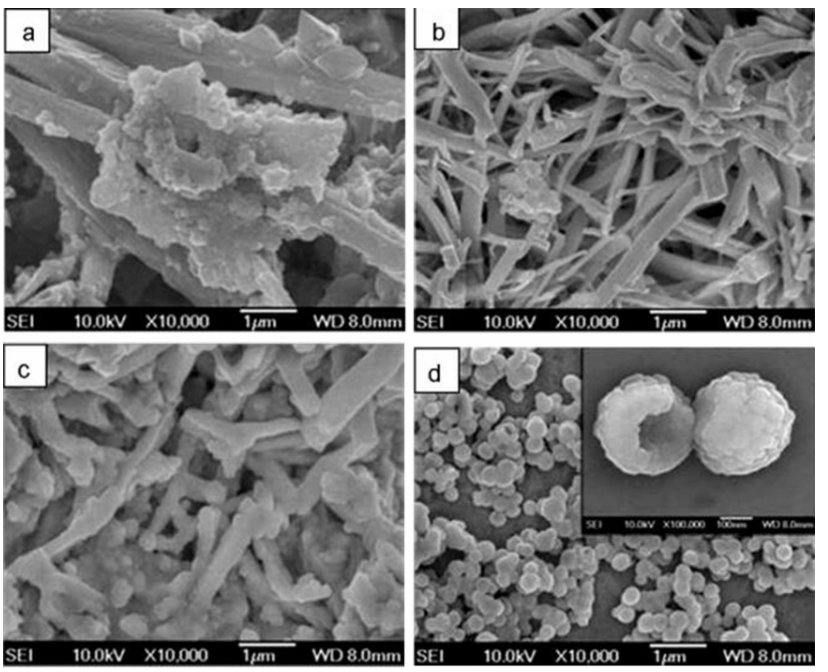

Fig. $2 \quad \mathrm{Y}_{2} \mathrm{Hf}_{2} \mathrm{O}_{7}$ powders prepared with different concentrations of surfactant: (a) $0 \%$, (b) $0.6 \%$, (c) $1.2 \%$, (d) $1.5 \%$, and calcined at $800{ }^{\circ} \mathrm{C}$ for $2 \mathrm{~h}$. Reproduced with permission from Ref. [73], (c) Elsevier B.V. 2009.

Though various morphologies can be obtained by co-precipitation method, agglomeration is inevitably observed in powders synthesized by this method, which is harmful for the sintering of transparent ceramics.

\section{5 Sol-gel method}

The sol-gel method offers considerable advantages of good mixing of the starting materials and excellent chemical homogeneity and phase purity of the synthesized powders. The molecular level mixing and the tendency of partially hydrolyzed species to form extended networks facilitate the structure evolution thereby lowering the crystallization temperature. Thus, it makes the preparation of particular phases possible at ambient and gentle conditions. Usually, organic solvent and stabilizer, such as acetylacetone, 2-methoxyethanol, and methanol, are used. A subsequent calcination process is also necessary to obtain the target powders. $\mathrm{La}_{2} \mathrm{Zr}_{2} \mathrm{O}_{7}$ and $\mathrm{La}_{1.96} \mathrm{Eu}_{0.04} \mathrm{Zr}_{2} \mathrm{O}_{7}$ [75], $\mathrm{Er}^{3+}$-doped $\mathrm{La}_{2} \mathrm{Ti}_{2} \mathrm{O}_{7}$ [76], and $\mathrm{Eu}^{3+} / \mathrm{Y}_{2} \mathrm{Ti}_{2} \mathrm{O}_{7}$ [77] powders were also examples synthesized by sol-gel method.

Stearic acid method (SAM) was a modified sol-gel method, in which stearic acid was used as solvent and dispersant. In 2008, cubic fluorite type $\mathrm{Y}_{2} \mathrm{Zr}_{2} \mathrm{O}_{7}$ nanocrystal was synthesized by SAM using zirconium nitrate and yttrium nitrate as raw materials [78]. Pechini method was also a kind of sol-gel method. In 2010, undoped and $\mathrm{Pr}$-doped $\mathrm{La}_{2} \mathrm{Hf}_{2} \mathrm{O}_{7}$ nanopowders were synthesized by Pechini reaction method [34], and 
pure cubic pyrochlore structure of $\mathrm{La}_{2} \mathrm{Hf}_{2} \mathrm{O}_{7}$ was formed at $1000{ }^{\circ} \mathrm{C}$.

Comparatively, sol-gel method is too complex as it involves too many processes and is time-consuming [75]. Then, relatively simple experimental processes were developed; for instance, the combustion method.

\section{6 Combustion method}

Combustion method is a simple and rapid method and is widely used to synthesize $\mathrm{A}_{2} \mathrm{~B}_{2} \mathrm{O}_{7}$ powders. The major advantages of the combustion process are: improvement in processing time, energy saving, and the high sintering activity of the combustion products. In this method, nitrate is the common raw material, and carbohydrazide [79], urea [79-81], glycine [41,80,82, 83], and ethylene diamine tetraacetic acid (EDTA) [41] or two of them are used as fuels. So far, $\mathrm{Ln}_{2} \mathrm{Zr}_{2} \mathrm{O}_{7}$ ( $\mathrm{Ln}=\mathrm{La}, \mathrm{Ce}, \mathrm{Pr}, \mathrm{Nd}, \mathrm{Sm}, \mathrm{Gd}$, and Dy) [79], $\mathrm{La}_{2} \mathrm{Zr}_{2} \mathrm{O}_{7}$ [81,82], $\mathrm{Y}_{2} \mathrm{Zr}_{2} \mathrm{O}_{7}$ [83], $\mathrm{Nd}_{2} \mathrm{Zr}_{2} \mathrm{O}_{7}$ [46], $\mathrm{La}_{2-x} \mathrm{Gd}_{x} \mathrm{Zr}_{2} \mathrm{O}_{7}$ [47,48,54], $\mathrm{LaLuZr}_{2} \mathrm{O}_{7}$ [84], $\mathrm{LaYZr}_{2} \mathrm{O}_{7}$ [85], $\mathrm{La}_{2} \mathrm{Hf}_{2} \mathrm{O}_{7}$ [41,51,52], $\quad \mathrm{Y}_{2} \mathrm{Hf}_{2} \mathrm{O}_{7}$ [86,87], $\mathrm{Lu}_{2} \mathrm{Hf}_{2} \mathrm{O}_{7}$ [80], and $\mathrm{La}_{2-x} \mathrm{Gd}_{x} \mathrm{Hf}_{2} \mathrm{O}_{7}$ [44] powders were synthesized by combustion method. The surface area, density, and morphology of the prepared powders are different when using different fuels $[41,79,80]$. It was attributed to the nature of the fuels that controls the energetics/ exothermicity of the combustion reaction [79]. In Liao et al.'s work [80], the effects of the fuel types and molar ratios of glycine-to-nitrate on the crystallinity and properties of $\mathrm{Y}_{2} \mathrm{Hf}_{2} \mathrm{O}_{7}$ were investigated. It showed that the crystallite size increased with the value of $\mathrm{f} / \mathrm{o}$ (fuel/oxidizer ratio) becoming close to stoichiometric ratio, resulting in the largest crystallite size at the stoichiometric ratio. The type of fuels can also affect the crystallinity and size of $\mathrm{Y}_{2} \mathrm{Hf}_{2} \mathrm{O}_{7}$ powders. The crystallite size of the powders increases in the order of glycine, urea, and the mixed fuels. The sample produced by the mixed of fuels method has more uniform size distribution, less agglomeration for the change of the reducing power of the fuel and the chelating effect of EDTA, which was added as a complexant.

Powders synthesized by combustion method have the similar morphology with porous network structure and are severely agglomerated (shown in Fig. 3(a)) [47]. The porous network structures may be originated from the release of gases, such as $\mathrm{CO}_{2}, \mathrm{~N}_{2}$, and $\mathrm{H}_{2} \mathrm{O}$ during the combustion process. The subsequent ball milling process can remove the agglomeration and destroy the porous network structure (Fig. 3(b)). This

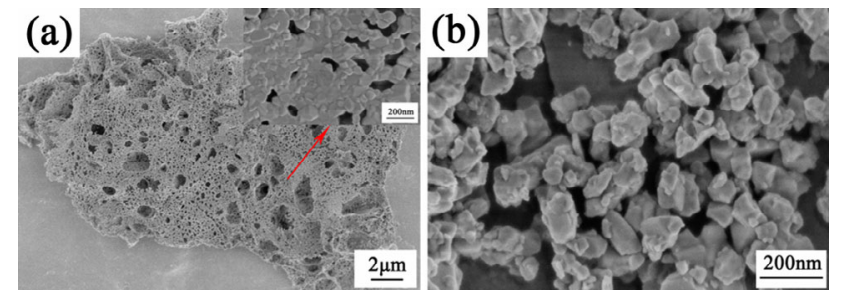

Fig. 3 Typical SEM images of powders synthesized by combustion method: (a) the as-burnt $\mathrm{LaGdZr}_{2} \mathrm{O}_{7}$ powders calcined at $800{ }^{\circ} \mathrm{C}$; (b) $\mathrm{LaGdZr}_{2} \mathrm{O}_{7}$ powders ball-milled for $20 \mathrm{~h}$. Reproduced with permission from Ref. [47], (C) Elsevier Ltd. 2012.

is helpful for the densification process when the powders are sintered to transparent ceramics.

In a word, $\mathrm{A}_{2} \mathrm{~B}_{2} \mathrm{O}_{7}$ powders were obtained by many synthesis methods mentioned above. Some of the methods are complex because of the addition of many organics. Combustion method is simple and rapid; it has been widely used to synthesize $\mathrm{A}_{2} \mathrm{~B}_{2} \mathrm{O}_{7}$ powders.

\section{Sintering methods of $\mathrm{A}_{2} \mathrm{~B}_{2} \mathrm{O}_{7}$ transparent ceramics}

The reported sintering methods for $\mathrm{A}_{2} \mathrm{~B}_{2} \mathrm{O}_{7}$ transparent ceramics included vacuum sintering, spark plasma sintering (SPS), hot isostatic pressing (HIP) sintering, and low-temperature high-pressure (LTHP) sintering.

\section{1 Vacuum sintering}

Vacuum sintering [88] refers to a sintering process carried out in a vacuum equipment to achieve better results than those run at atmospheric pressure. Vacuum sintering is typically used to fabricate oxide transparent ceramics, like garnet [12], $\mathrm{Y}_{2} \mathrm{O}_{3}[3], \mathrm{Lu}_{2} \mathrm{O}_{3}$ [10], and so on. The sintering temperature carried out is relatively high and usually $200{ }^{\circ} \mathrm{C}$ below the melting point of the ceramic body, while the vacuum sintering furnace is relatively cheap and the operation is simple. Also, no pressure is needed.

Most of the reported $\mathrm{A}_{2} \mathrm{~B}_{2} \mathrm{O}_{7}$ transparent ceramics were fabricated by vacuum sintering without any atmosphere. For example, $\mathrm{Y}_{2} \mathrm{Hf}_{2} \mathrm{O}_{7}$ transparent ceramic [86] was fabricated by vacuum sintering. First, the cold isostatic pressed (CIPed) green body was pre-sintered at $1200{ }^{\circ} \mathrm{C}$ for $2 \mathrm{~h}$ to remove the residual organics originated from the forming process (compacting process). Then, the samples were vacuum sintered at $1800-1950{ }^{\circ} \mathrm{C}$ for $6 \mathrm{~h}$ with a vacuum degree of $10^{-3} \mathrm{~Pa}$. 
This method was also carried out to prepare transparent ceramics such as $\mathrm{Y}_{2} \mathrm{Zr}_{2} \mathrm{O}_{7}$ [83], $\mathrm{La}_{2-x} \mathrm{Gd}_{x} \mathrm{Zr}_{2} \mathrm{O}_{7}$ [47,48, 56], $\mathrm{Eu}^{3+}: \mathrm{La}_{2-x} \mathrm{Gd}_{x} \mathrm{Zr}_{2} \mathrm{O}_{7}$ [53], $\mathrm{La}_{2-x} \mathrm{Lu}_{x} \mathrm{Zr}_{2} \mathrm{O}_{7}$ [49,84], $\mathrm{LaYZr}_{2} \mathrm{O}_{7}$ [85], $\mathrm{Y}_{2} \mathrm{Hf}_{2} \mathrm{O}_{7}$ [87], $\mathrm{La}_{2-x} \mathrm{Y}_{x} \mathrm{Hf}_{2} \mathrm{O}_{7}$ [90], $\mathrm{La}_{2-x} \mathrm{Gd}_{x} \mathrm{Hf}_{2} \mathrm{O}_{7}[43,44]$, and $\mathrm{Eu}^{3+}: \mathrm{La}_{0.8} \mathrm{Gd}_{1.2} \mathrm{Hf}_{2} \mathrm{O}_{7}$ [54].

Some of the $\mathrm{A}_{2} \mathrm{~B}_{2} \mathrm{O}_{7}$ transparent ceramics were fabricated by vacuum sintering in hydrogen or helium. $\mathrm{La}_{2} \mathrm{Hf}_{2} \mathrm{O}_{7}$ [41], $\mathrm{Gd}_{2} \mathrm{Hf}_{2} \mathrm{O}_{7}$ [89], $\mathrm{La}_{2} \mathrm{Hf}_{2} \mathrm{O}_{7}: \mathrm{Tb}$ [51], $\mathrm{La}_{2} \mathrm{Hf}_{2} \mathrm{O}_{7}: \mathrm{Ti}$ [52], and $\mathrm{Nd}_{2} \mathrm{Zr}_{2} \mathrm{O}_{7}$ [46] transparent ceramics were all fabricated by sintering the compacted green body in $\mathrm{H}_{2}$ atmosphere.

Usually, the post-annealing process is necessary for vacuum sintering of most transparent ceramics. After sintering in vacuum, oxygen vacancies would generate as the vacuum atmosphere is a kind of anoxic environment. As the oxygen vacancies can produce strong light absorption through the formation of color centers, which would lead to the coloration of the ceramics. The post-annealing process could supply oxygen from air and eliminate the coloration of the ceramics, so as to obtain higher transparency $[53,54,56]$.

For this sintering method, the usual average grain sizes of single phase transparent ceramics were about several micrometers to tens of micrometers, and were relatively larger than other methods in which pressure is used, while the grain size would decrease when two phases coexisted in the transparent ceramics, like in $\mathrm{La}_{2-x} \mathrm{Lu}_{x} \mathrm{Zr}_{2} \mathrm{O}_{7}$ system ceramics [49]. When $x$ ranged from 0.6 to 1.2 , pyrochlore and defective fluorite phases coexisted and the average grain sizes were only $2-5 \mu \mathrm{m}$.

\section{2 Spark plasma sintering}

Spark plasma sintering (SPS) [88] is a method for obtaining fully dense and fine-grained transparent ceramics at low temperatures within short time durations. It is also known as field-assisted sintering or pulsed electric current sintering. SPS has been used to fabricate transparent ceramics because of its characteristic fast densification without significant grain growth. By controlling the sintering parameters, such as temperature, heating rate, pressure, dwell time, and atmosphere, highly transparent ceramics can be produced [91].

In 2011, An et al. [45,50] fabricated $\mathrm{La}_{2} \mathrm{Zr}_{2} \mathrm{O}_{7}$ and $\mathrm{Lu}_{2} \mathrm{Ti}_{2} \mathrm{O}_{7}$ transparent ceramics by reactive spark plasma sintering. The sintering temperature was as low as 1400 and $1500{ }^{\circ} \mathrm{C}$ respectively, with a pressure of $100 \mathrm{MPa}$ and short holding time (45 min). However, the transmittance of the ceramics in the visible range was relatively low. As a graphite die was used in SPS, carbon contaminant was introduced and lowered the optical quality.

\section{3 Hot isostatic pressing sintering}

For some transparent ceramics, simple vacuum sintering or pressureless sintering cannot produce high density, thus high external force is needed, like high pressure. Hot isostatic pressing (HIP) sintering becomes a good choice. HIP [88] is a manufacturing process used to achieve the maximum possible densification, which is a key to reach high light transmittance for transparent ceramics. To reduce the fabrication cost, HIP is usually used as the last step followed by vacuum sintering or pressureless sintering. It has been widely used to synthesize transparent armor ceramics, such as submicron grained alumina $\left(\mathrm{Al}_{2} \mathrm{O}_{3}\right)$ [92] and spinel $\left(\mathrm{MgAl}_{2} \mathrm{O}_{4}\right)$ [93]. Nowadays, HIP process was also used to prepare cubic sesquioxide ceramics, including $\mathrm{Y}_{2} \mathrm{O}_{3}$ [94], $\mathrm{Sc}_{2} \mathrm{O}_{3}$ [95], and $\mathrm{Lu}_{2} \mathrm{O}_{3}$ [11]. In these cases, vacuum sintering was first used to remove closed porosity, and then a subsequent HIP step was employed. HIP process can be also combined with hot pressing (HP). HP followed by HIP was proved to be more feasible to fabricate transparent $\mathrm{MgAl}_{2} \mathrm{O}_{4}$ ceramics.

As a high-cost sintering method, HIP sintering is not widely used in fabricating $\mathrm{A}_{2} \mathrm{~B}_{2} \mathrm{O}_{7}$ transparent ceramics. In Schott Company's US patent [96], solid state reactive sintering of $\mathrm{Y}_{2} \mathrm{Ti}_{2} \mathrm{O}_{7}$ was carried out by vacuum sintering in hydrogen or helium at $1500{ }^{\circ} \mathrm{C}$ for $3 \mathrm{~h}$ and then HIP at $1700{ }^{\circ} \mathrm{C}$ for $1 \mathrm{~h}-\mathrm{Ar}-200 \mathrm{MPa}$. Afterwards, the ceramics were reoxidized in a further thermal step (for example $900{ }^{\circ} \mathrm{C}, 5 \mathrm{~h}$, in air) and optically transparent and homogeneous bodies were obtained. $\mathrm{Yb}_{2} \mathrm{Ti}_{2} \mathrm{O}_{7}$ transparent ceramic was also fabricated by similar process. In another US patent [74], $\mathrm{Gd}_{2} \mathrm{Hf}_{2} \mathrm{O}_{7}$ : $\mathrm{Ce}$ and other $\mathrm{A}_{2} \mathrm{X}_{2} \mathrm{O}_{7}$ transparent ceramic scintillator bodies were sintered by two-step method. For $\mathrm{Gd}_{2} \mathrm{Hf}_{2} \mathrm{O}_{7}$ : Ce, the CIPed pellets were first sintered in air at $1500-1600{ }^{\circ} \mathrm{C}$ for $3 \mathrm{~h}$, and then HIPed at $1400-1600{ }^{\circ} \mathrm{C}$ for $1 \mathrm{~h}$ in argon at approximately $30 \mathrm{ksi}$. To achieve high optical quality, the sintering technology still needs to be adjusted and optimized.

\section{4 Low-temperature high-pressure process}

Low-temperature high-pressure (LTHP) process is similar to the HP process, but with higher pressure (in GPa grade). This method can be successfully applied for densification of nanocrystalline powders into transparent ceramics and is competitive to restrain the small grain 
size in the product. For example, nanocrystalline $\mathrm{MgAl}_{2} \mathrm{O}_{4}$ and $\mathrm{YAG}$ transparent ceramics $[97,98]$ were fabricated by this method. For $\mathrm{MgAl}_{2} \mathrm{O}_{4}$ nanocrystalline transparent ceramic, the optimal sintering condition has been determined to be around $620{ }^{\circ} \mathrm{C} / 3.7 \mathrm{GPa}$, and the average grain size was only about $61 \mathrm{~nm}$. For Pr:YAG nanoceramic, the LTHP sintering condition was $450{ }^{\circ} \mathrm{C} / 8 \mathrm{GPa}$ for $1 \mathrm{~min}$ with a transmittance of $51 \%$ at $1250 \mathrm{~nm}$. The average grain size was only about $24 \mathrm{~nm}$.

In 2014, Trojan-Piegza et al. [42] fabricated $\mathrm{La}_{2} \mathrm{Hf}_{2} \mathrm{O}_{7}: \operatorname{Pr}$ transparent ceramic by LTHP sintering technique using nanopowders made by Pechini method. The CIPed pellets were sintered in a graphite die at a pressure ranging in the $2-8 \mathrm{GPa}$ at different temperatures between 300 and $1500{ }^{\circ} \mathrm{C}$. And the time of sintering varied from 1 to $20 \mathrm{~min}$. Results showed that the samples sintered at $1400{ }^{\circ} \mathrm{C}$ for 2 min and additionally at $900{ }^{\circ} \mathrm{C}$ for another $10 \mathrm{~min}$ in one continuous run were found to be of highest translucency. The average grain size of the samples was about $150 \mathrm{~nm}$.

Though this method can obtain transparent nanoceramics, the transparency was not as good as transparent ceramics obtained by other sintering methods. If higher mechanical properties of the ceramics were required, this LTHP method is an option because of its significantly effect of restraining grain size.

\section{$5 \quad \mathrm{~A}_{2} \mathrm{~B}_{2} \mathrm{O}_{7}$ system transparent ceramics with different compositions}

For $\mathrm{A}_{2} \mathrm{~B}_{2} \mathrm{O}_{7}$ system transparent ceramics, the common forming method was dry pressing and cold isostatic pressing. Only a few researchers used the wet molding technique, like slip casting [85]. After sintered by different methods mentioned in the last part, $\mathrm{A}_{2} \mathrm{~B}_{2} \mathrm{O}_{7}$ system transparent ceramics were obtained. Fabrication method and properties of the reported $\mathrm{A}_{2} \mathrm{~B}_{2} \mathrm{O}_{7}$ system transparent ceramics are summarized in Table 1 . In this

Table 1 Fabrication method and properties of the reported $A_{2} B_{2} O_{7}$ system transparent ceramics

\begin{tabular}{|c|c|c|c|c|c|c|c|}
\hline Compound & $\begin{array}{l}\text { Powder synthesis } \\
\text { method }\end{array}$ & Sintering method & $r_{\mathrm{A} /} r_{\mathrm{B}}$ & Crystal structure $^{*}$ & $\begin{array}{l}\text { Density } \\
\left(\mathrm{g} / \mathrm{cm}^{3}\right)\end{array}$ & Transmittance $(\%)$ & $\begin{array}{l}\text { Refractive } \\
\text { index }\end{array}$ \\
\hline $\mathrm{La}_{2} \mathrm{Hf}_{2} \mathrm{O}_{7}[41,89]$ & Combustion method & $\begin{array}{l}\text { Pressureless } \\
\text { sintering in } \mathrm{H}_{2}\end{array}$ & 1.63 & $\mathrm{P}$ & 7.93 & $>70 \%(633 \mathrm{~nm}, 0.6 \mathrm{~mm})$ & - \\
\hline $\mathrm{Gd}_{2} \mathrm{Hf}_{2} \mathrm{O}_{7}[89]$ & Combustion method & $\begin{array}{l}\text { Pressureless } \\
\text { sintering in } \mathrm{H}_{2}\end{array}$ & 1.483 & $\mathrm{P}$ & 9.38 & $>70 \%(633 \mathrm{~nm}, 0.6 \mathrm{~mm})$ & - \\
\hline $\mathrm{Y}_{2} \mathrm{Hf}_{2} \mathrm{O}_{7}[86]$ & Combustion method & Vacuum sintering & 1.435 & $\mathrm{~F}$ & 7.54 & $>50 \%(633 \mathrm{~nm}, 1 \mathrm{~mm})$ & - \\
\hline $\mathrm{Y}_{2} \mathrm{Hf}_{2} \mathrm{O}_{7}[87]$ & $\begin{array}{l}\text { Solid state reactive } \\
\text { method }\end{array}$ & Vacuum sintering & 1.435 & $\mathrm{~F}$ & 7.54 & $>60 \%(633 \mathrm{~nm}, 1 \mathrm{~mm})$ & $\begin{array}{c}2.018 \\
(600 \mathrm{~nm})\end{array}$ \\
\hline $\mathrm{La}_{2-x} \mathrm{Y}_{x} \mathrm{Hf}_{2} \mathrm{O}_{7}[90]$ & Solid state method & Vacuum sintering & $1.435-1.63$ & $\begin{array}{l}x<0.4: \mathrm{F} \\
x \geqslant 0.4: \mathrm{P}\end{array}$ & $7.54-7.93$ & $\begin{array}{l}x=1.2: 75.3 \%(633 \mathrm{~nm}, \\
1 \mathrm{~mm})\end{array}$ & $\begin{array}{c}x=1.2: 2.04 \\
(633 \mathrm{~nm})\end{array}$ \\
\hline $\mathrm{LaGdHf}_{2} \mathrm{O}_{7}[43]$ & Solid state method & Vacuum sintering & 1.56 & $\mathrm{P}$ & 8.37 & $74 \%(1100 \mathrm{~nm}, 1 \mathrm{~mm})$ & - \\
\hline $\mathrm{La}_{2} \mathrm{Hf}_{2} \mathrm{O}_{7}: \operatorname{Pr}[42]$ & Pechini method & LTHP & - & $\mathrm{P}$ & 7.74 & $\sim 38 \%(900 \mathrm{~nm}, 1 \mathrm{~mm})$ & - \\
\hline $\mathrm{La}_{2-x} \mathrm{Gd}_{x} \mathrm{Hf}_{2} \mathrm{O}_{7}[44]$ & Combustion method & Vacuum sintering & $1.483-1.63$ & $\mathrm{P}$ & $7.91-8.88$ & $\begin{array}{l}x=1.2: 76.1 \%(800 \mathrm{~nm}, \\
1 \mathrm{~mm})\end{array}$ & $\begin{array}{c}\sim 2.05 \\
(633 \mathrm{~nm})\end{array}$ \\
\hline $\mathrm{Gd}_{2} \mathrm{Zr}_{2} \mathrm{O}_{7}[99]$ & & $\begin{array}{l}\text { Vacuum sintering + } \\
\text { HIP }\end{array}$ & 1.46 & $\mathrm{P}$ & 6.93 & - & - \\
\hline $\mathrm{La}_{2} \mathrm{Zr}_{2} \mathrm{O}_{7}[45]$ & & SPS & 1.61 & $P$ & 6.057 & $68 \%(4-6 \mu \mathrm{m}, 1 \mathrm{~mm})$ & - \\
\hline $\mathrm{Y}_{2} \mathrm{Zr}_{2} \mathrm{O}_{7}[83]$ & Combustion method & Vacuum sintering & 1.42 & F & & $68 \%(633 \mathrm{~nm}, 1 \mathrm{~mm})$ & - \\
\hline $\mathrm{Nd}_{2} \mathrm{Zr}_{2} \mathrm{O}_{7}[46]$ & Combustion method & $\begin{array}{l}\text { Pressureless } \\
\text { sintering in } \mathrm{H}_{2}\end{array}$ & 1.54 & $\mathrm{P}$ & & $>60 \%(633 \mathrm{~nm}, 1 \mathrm{~mm})$ & - \\
\hline $\begin{array}{l}\mathrm{La}_{2-x} \mathrm{Gd}_{x} \mathrm{Zr}_{2} \mathrm{O}_{7} \\
{[47,48]}\end{array}$ & Combustion method & Vacuum sintering & $1.46-1.61$ & 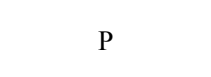 & $6.01-6.72$ & $\begin{array}{l}x=0.4: 73.6 \%(1100 \mathrm{~nm}, \\
1 \mathrm{~mm})\end{array}$ & $\begin{array}{c}\sim 2.08 \\
(633 \mathrm{~nm})\end{array}$ \\
\hline $\mathrm{La}_{2-x} \mathrm{Lu}_{x} \mathrm{Zr}_{2} \mathrm{O}_{7}[49]$ & Solid state method & Vacuum sintering & $1.36-1.61$ & $\begin{array}{c}x<0.4: \mathrm{F} \\
0.4 \leqslant x \leqslant 1.2: \\
\mathrm{P}+\mathrm{F} ; x \geqslant 1.4: \mathrm{F}\end{array}$ & $5.94-7.84$ & $\begin{array}{l}x=1.2: 72.4 \%(1100 \mathrm{~nm}, \\
1 \mathrm{~mm})\end{array}$ & - \\
\hline $\mathrm{LaLuZr}_{2} \mathrm{O}_{7}[84]$ & Combustion method & Vacuum sintering & 1.48 & $\mathrm{P}+\mathrm{F}$ & 6.82 & $73.4 \%(1100 \mathrm{~nm}, 1 \mathrm{~mm})$ & - \\
\hline $\mathrm{LaYZr}_{2} \mathrm{O}_{7}[85]$ & Combustion method & Vacuum sintering & 1.51 & $\mathrm{P}$ & 5.81 & $74.3 \%(633 \mathrm{~nm}, 1 \mathrm{~mm})$ & $\begin{array}{c}2.07 \\
(633 \mathrm{~nm})\end{array}$ \\
\hline $\mathrm{Y}_{2} \mathrm{Ti}_{2} \mathrm{O}_{7}[96]$ & Solid state method & $\begin{array}{l}\text { Vacuum sintering }+ \\
\text { HIP }\end{array}$ & 1.68 & $\mathrm{P}$ & 5.03 & - & - \\
\hline $\mathrm{Y}_{2+x} \mathrm{Ti}_{2} \mathrm{O}_{7+3 x / 2}[102]$ & Solid state method & Vacuum sintering & 1.68 & $\mathrm{P}$ & $99.89 \%$ & $\begin{array}{l}x=0.04: 49.9 \%(1100 \mathrm{~nm}, \\
0.5 \mathrm{~mm})\end{array}$ & $\begin{array}{c}2.20 \\
(560 \mathrm{~nm})\end{array}$ \\
\hline $\mathrm{Lu}_{2} \mathrm{Ti}_{2} \mathrm{O}_{7}[50]$ & Solid state method & SPS & 1.61 & $\mathrm{P}$ & $99.7 \%$ & $40 \%(550 \mathrm{~nm}, 1 \mathrm{~mm})$ & $\begin{array}{c}2.57 \\
(633 \mathrm{~nm}) \\
\end{array}$ \\
\hline
\end{tabular}

${ }^{*} \mathrm{P}=$ pyrochlore; $\mathrm{F}=$ defective fluorite. 
part, $\mathrm{A}_{2} \mathrm{Hf}_{2} \mathrm{O}_{7}, \mathrm{~A}_{2} \mathrm{ZrO}_{7}$, and $\mathrm{A}_{2} \mathrm{Ti}_{2} \mathrm{O}_{7}$ three system transparent ceramics were mainly introduced.

\section{5. $1 \mathrm{~A}_{2} \mathrm{Hf}_{2} \mathrm{O}_{7}$ system transparent ceramics}

The $\mathrm{A}_{2} \mathrm{Hf}_{2} \mathrm{O}_{7}$ system transparent ceramics were first developed for the potential application as new scintillators. In 2003, a bright and fast luminescence, characterized by $\mathrm{Ce}^{3+}$ interconfiguration $5 \mathrm{~d} \rightarrow 4 \mathrm{f}$ transition, was observed in Ce-doped $\mathrm{La}_{2} \mathrm{Hf}_{2} \mathrm{O}_{7}$ compound (powders) obtained by solid state reaction [100]. Then, $\mathrm{Ce}: \mathrm{La}_{2} \mathrm{Hf}_{2} \mathrm{O}_{7}$ began to be paid much attention as a new heavy and fast scintillator. As the growth of large size $\mathrm{La}_{2} \mathrm{Hf}_{2} \mathrm{O}_{7}$ single crystal was very difficult due to its high melting point, Ji et al. [41,89] successfully fabricated $\mathrm{La}_{2} \mathrm{Hf}_{2} \mathrm{O}_{7}$ and $\mathrm{Gd}_{2} \mathrm{Hf}_{2} \mathrm{O}_{7}$ transparent ceramics for the first time in 2005 (Fig. 4 and Fig. 5). The powders were synthesized by combustion method and the transparent ceramics were obtained by sintering at $1850{ }^{\circ} \mathrm{C}$ in $\mathrm{H}_{2}$ atmosphere. However, fast decay derived from $5 \mathrm{~d} \rightarrow 4 \mathrm{f}$ transition of $\mathrm{Ce}^{3+}$ was not observed, and many studies were carried out and got the same results, which was not consistent with Borisevich et al.'s research in 2003 [100]. Chaudhry et al. [57] proposed an idea in 2011 that Ce-doped $\mathrm{RE}_{2} \mathrm{M}_{2} \mathrm{O}_{7}(\mathrm{RE}=\mathrm{Y}, \mathrm{La} ; \mathrm{M}=\mathrm{Ti}, \mathrm{Zr}, \mathrm{Hf})$ were a class of non-scintillators. Basing on the first-principle, they performed electronic structure calculation of these compounds, and found that the Ce $5 \mathrm{~d}$ state lies above the CBM (conduction band minimum) (Fig. 6), which would prevent any luminescence from the $\mathrm{Ce}$ site. These studies made the enthusiasm on research of this kind of transparent ceramics gradually decreased, especially on the fast decay scintillation applications with $\mathrm{Ce}^{3+}$ doping. The luminescence of $\mathrm{Tb}^{3+}$ in the A-site and $\mathrm{Ti}^{4+}$ in the $\mathrm{Hf}^{4+}$ site for $\mathrm{La}_{2} \mathrm{Hf}_{2} \mathrm{O}_{7}$ ceramic was reported in 1984 [101], and the emission of $\mathrm{La}_{2} \mathrm{Hf}_{1.98} \mathrm{Ti}_{0.02} \mathrm{O}_{7}$ had an intensity of about 1.6 times that of PAR $\mathrm{CaWO}_{4}$, which would be of interest as an $\mathrm{X}$-ray intensifying screen phosphor. Thus, Ji et al. fabricated $\mathrm{La}_{2} \mathrm{Hf}_{2} \mathrm{O}_{7}: \mathrm{Tb}$ [51] and $\mathrm{La}_{2} \mathrm{Hf}_{2} \mathrm{O}_{7}: \mathrm{Ti}$ [52] transparent ceramics. The luminescence properties of these transparent ceramics were also studied. For $\mathrm{La}_{2} \mathrm{Hf}_{2} \mathrm{O}_{7}$ :Ti transparent ceramic, the broad emission band centered at $475 \mathrm{~nm}$ originated from the oxide-Ti ${ }^{4+}$ charge-transfer transitions, which rendered fast decay time on the order of $10 \mu \mathrm{s}$. It was comparable to that of $\mathrm{Gd}_{2} \mathrm{O}_{2} \mathrm{~S}$ :Pr ceramic scintillator $(3 \mu \mathrm{s})$ and much faster than that of $(\mathrm{Y}, \mathrm{Gd})_{2} \mathrm{O}_{3}: \mathrm{Eu}$ ceramic scintillator $(1000$ $\mu \mathrm{s})$. The highest relative light output reached about 1.5 times that of $\mathrm{Bi}_{4} \mathrm{Ge}_{3} \mathrm{O}_{12}$ (BGO) single crystal when

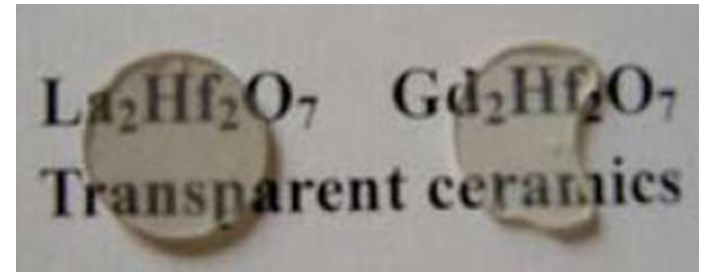

Fig. 4 Photograph of $\mathrm{Ln}_{2} \mathrm{Hf}_{2} \mathrm{O}_{7}(\mathrm{Ln}=\mathrm{La}, \mathrm{Gd})$ ceramics sintered at $1850{ }^{\circ} \mathrm{C}$ for $6 \mathrm{~h}$. Reproduced with permission from Ref. [89], (c) Chinese Academy of Sciences 2006.

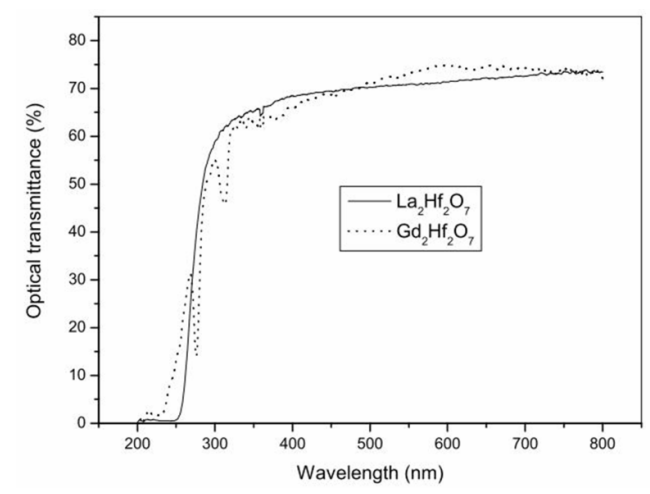

Fig. 5 Transmittance of $\operatorname{Ln}_{2} \mathrm{Hf}_{2} \mathrm{O}_{7}$ ( $\left.\mathrm{Ln}=\mathrm{La}, \mathrm{Gd}\right)$ transparent ceramics sintered at $1850{ }^{\circ} \mathrm{C}$ for $6 \mathrm{~h}$. Reproduced with permission from Ref. [89], (C) Chinese Academy of Sciences 2006.

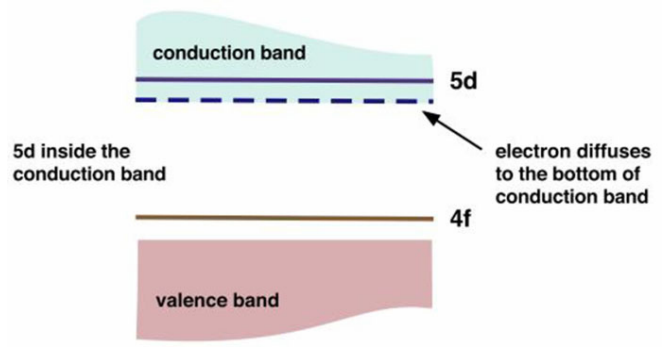

Fig. 6 Simple schematic model to illustrate the scenario for no $\mathrm{Ce}^{3+}$ luminescence: lowest $\mathrm{Ce} 5 \mathrm{~d}$ inside the host conduction band. Reproduced with permission from Ref. [57], C American Institute of Physics 2011.

excited by $120 \mathrm{kV}$ X-rays. Thus, $\mathrm{La}_{2} \mathrm{Hf}_{2} \mathrm{O}_{7}$ :Ti transparent ceramic is very promising as scintillator materials for X-ray CT detector applications, while some other properties such as afterglow and radiation damage are also crucial for the X-ray CT imaging, but they were not studied further.

In 2011, Zou et al. [86] prepared $\mathrm{Y}_{2} \mathrm{Hf}_{2} \mathrm{O}_{7}$ transparent ceramic by vacuum sintering. The $\mathrm{Y}_{2} \mathrm{Hf}_{2} \mathrm{O}_{7}$ powders were synthesized by combustion method with EDTA as the fuel. The ceramic showed a transmittance of $50 \%$ ( $1 \mathrm{~mm}$ thick) in the visible spectral region. Further, Zhou et al. [87] optimized this process and the 


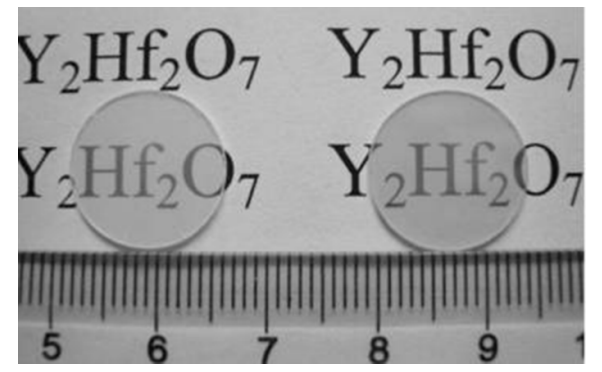

Fig. 7 Photograph of the mirror-polished $\mathrm{Y}_{2} \mathrm{Hf}_{2} \mathrm{O}_{7}$ transparent ceramics $\left(1 \mathrm{~mm}\right.$ thick) sintered at $1900{ }^{\circ} \mathrm{C}$ for $6 \mathrm{~h}$ (left) and $12 \mathrm{~h}$ (right), respectively. Reproduced with permission from Ref. [87], (C) Elsevier B.V. 2012.

transmittance of the $\mathrm{Y}_{2} \mathrm{Hf}_{2} \mathrm{O}_{7}$ ceramic (Fig. 7) was improved to $60 \%$ (1 $\mathrm{mm}$ thick) in the visible spectra region (Fig. 8). With the refractive index 2.018, the calculated theoretical transmittance was about $78.5 \%$. That is, the prepared $\mathrm{Y}_{2} \mathrm{Hf}_{2} \mathrm{O}_{7}$ transparent ceramic reached $76 \%$ of the theoretical transmittance.

$\mathrm{A}_{2} \mathrm{Hf}_{2} \mathrm{O}_{7}$ transparent ceramics with two elements in A site were also studied. In 2011, $\mathrm{La}_{2-x} \mathrm{Y}_{x} \mathrm{Hf}_{2} \mathrm{O}_{7}$ system transparent ceramics (Fig. 9) were fabricated [90] by solid state reaction sintering in vacuum at $1900{ }^{\circ} \mathrm{C}$, and phase transition (Fig. 10) occurred with the increase

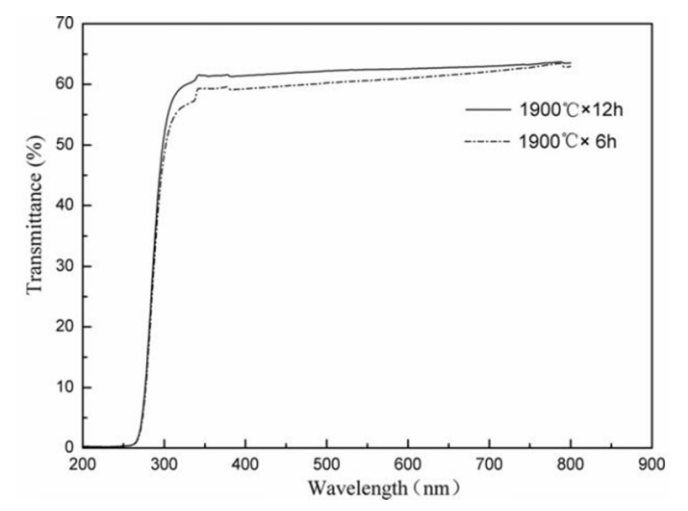

Fig. 8 Transmittance of the mirror-polished $\mathrm{Y}_{2} \mathrm{Hf}_{2} \mathrm{O}_{7}$ transparent ceramics (1 mm thick). Reproduced with permission from Ref. [87], (C) Elsevier B.V. 2012.

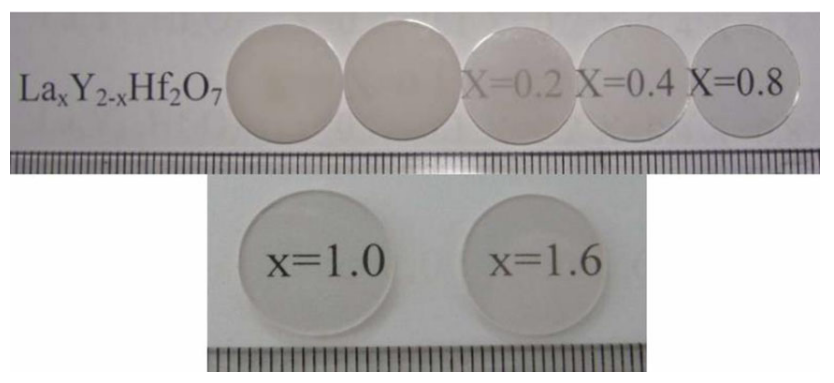

Fig. 9 Photograph of $\mathrm{La}_{2-x} \mathrm{Y}_{x} \mathrm{Hf}_{2} \mathrm{O}_{7}$ ceramics $(x=0-1.6)$ (polished, $1 \mathrm{~mm}$ thick). Reproduced with permission from Ref. [90], (C) Chinese Academy of Sciences 2011.

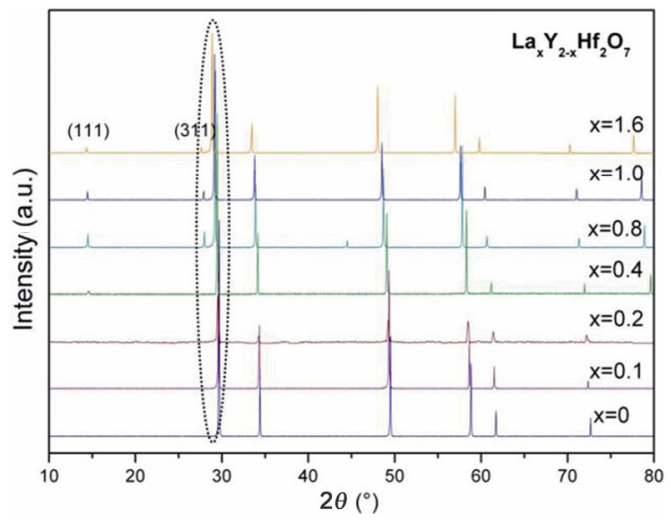

Fig. 10 XRD patterns of $\mathrm{La}_{2-x} \mathrm{Y}_{x} \mathrm{Hf}_{2} \mathrm{O}_{7}$ ceramics $(x=0$ 1.6) sintered at $1900{ }^{\circ} \mathrm{C}$ for $6 \mathrm{~h}$. Reproduced with permission from Ref. [90], (C) Chinese Academy of Sciences 2011.

of $x$. When $x<0.4$, defective fluorite structure was presented, while pyrochlore structure showed up when $x \geqslant 0.4$. It was consistent with Subramanian et al.'s theory [55]. Meanwhile, Yi et al. [43] reported $\mathrm{LaGdHf}_{2} \mathrm{O}_{7}$ transparent ceramic, which was prepared by solid state method and vacuum sintering at $1900{ }^{\circ} \mathrm{C}$. The transmittance reached to $74 \%$ at $1100 \mathrm{~nm}$.

Combined with the high density and effective atomic number, $\mathrm{La}_{2-x} \mathrm{Y}_{x} \mathrm{Hf}_{2} \mathrm{O}_{7}$ and $\mathrm{LaGdHf}_{2} \mathrm{O}_{7}$ transparent ceramics were considered as promising candidates for scintillator host. However, the sintering temperature was so high that the energy consumption and equipment loss were large. Therefore, it is imperative to develop new methods to reduce the sintering temperature. In 2014, Trojan-Piegza et al. [42] fabricated $\mathrm{La}_{2} \mathrm{Hf}_{2} \mathrm{O}_{7}: \mathrm{Pr}$ transparent ceramic by a new low-temperature highpressure (LTHP) sintering method. The sintering temperature was as low as $1400{ }^{\circ} \mathrm{C}$, the holding time was $2 \mathrm{~min}$, and the transmittance was very low (Fig. 11). Moreover, after annealing in air at $900{ }^{\circ} \mathrm{C}$ for $5 \mathrm{~h}$, which was required to remove the dark color, the opacity enhanced unfortunately. The expected $5 \mathrm{~d}-4 \mathrm{f}$ transition of $\mathrm{Pr}^{3+}$ was not detected and only $4 \mathrm{f}-4 \mathrm{f}$ transition was presented, indicating that fast decay also would not happen in $\mathrm{La}_{2} \mathrm{Hf}_{2} \mathrm{O}_{7}: \mathrm{Pr}$ scintillator. In 2016, Wang et al. [44] reported the $\mathrm{La}_{2-x} \mathrm{Gd}_{x} \mathrm{Hf}_{2} \mathrm{O}_{7}$ system transparent ceramics (Fig. 12). They were fabricated through vacuum sintering from nanopowders synthesized by combustion method. All the ceramics were transparent after being sintered at $1830{ }^{\circ} \mathrm{C}$ for $6 \mathrm{~h}$, and the sintering temperature was lower than that of $\mathrm{Yi}$ et al.'s [43] work, indicating that powders synthesized by combustion method have higher sintering activity and can effectively lower the sintering temperature. The highest in-line transmittance was $76.1 \%$ at $800 \mathrm{~nm}$ 


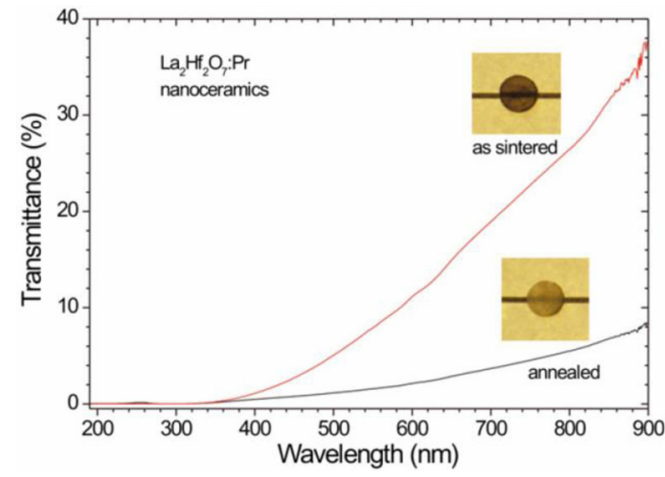

Fig. 11 Transmittance of $\mathrm{La}_{2} \mathrm{Hf}_{2} \mathrm{O}_{7}: \mathrm{Pr}$ ceramics before and after annealing ( $\sim 1 \mathrm{~mm}$ thick; inset: their photos). Reproduced with permission from Ref. [42], (C) John Wiley and Sons 2014.

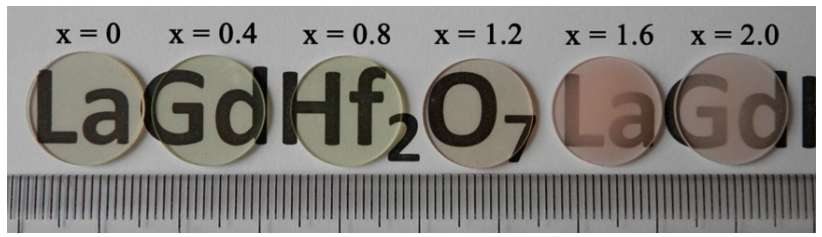

Fig. 12 Photograph of $\mathrm{La}_{2-x} \mathrm{Gd}_{x} \mathrm{Hf}_{2} \mathrm{O}_{7}$ transparent ceramics vacuum sintered at $1830{ }^{\circ} \mathrm{C}$ for $6 \mathrm{~h}$ and annealed at $1500{ }^{\circ} \mathrm{C}$ for $5 \mathrm{~h}$ in air ( $1 \mathrm{~mm}$ thick). Reproduced with permission from Ref. [44], (C) Elsevier B.V. 2015.

$(x=1.2)$. The thermally etched surface and fracture surface of the ceramics were shown in Fig. 13 and Fig. 14. Typically, the grain size sintered in vacuum was in micron scale and the main fracture mode was transgranular. As Gd content increased, the density of the ceramics linearly increased from $7.91 \mathrm{~g} / \mathrm{cm}^{3}(x=0)$ to $8.88 \mathrm{~g} / \mathrm{cm}^{3}(x=2.0)$. Meanwhile, the corresponding lattice parameters decreased linearly. With high density and high effective atomic number, the $\mathrm{La}_{2-x} \mathrm{Gd}_{x} \mathrm{Hf}_{2} \mathrm{O}_{7}$ $(x=0-2.0)$ transparent ceramics are promising candidates for scintillator hosts.

\section{5. $2 \mathrm{~A}_{2} \mathrm{Zr}_{2} \mathrm{O}_{7}$ system transparent ceramics}

In 2008, Murata Manufacturing Co., Ltd. reported in a US patent [60] that a series of $\mathrm{A}_{x} \mathrm{~B}_{y} \mathrm{O}_{w}$ translucent ceramics were fabricated by sintering in $98 \mathrm{vol} \%$ oxygen atmosphere. In their experimental examples, $\mathrm{La}_{2} \mathrm{Zr}_{2} \mathrm{O}_{7}$, $\mathrm{Y}_{2} \mathrm{Zr}_{2} \mathrm{O}_{7}, \mathrm{Gd}_{2} \mathrm{Zr}_{2} \mathrm{O}_{7}$, and $\mathrm{La}_{1.6} \mathrm{Y}_{0.4} \mathrm{Zr}_{2} \mathrm{O}_{7}, \mathrm{La}_{1.2} \mathrm{Y}_{0.8} \mathrm{Zr}_{2} \mathrm{O}_{7}$, $\mathrm{La}_{1.6} \mathrm{Gd}_{0.4} \mathrm{Zr}_{2} \mathrm{O}_{7}, \quad \mathrm{La}_{1.2} \mathrm{Gd}_{0.8} \mathrm{Zr}_{2} \mathrm{O}_{7}, \quad \mathrm{La}_{1.6} \mathrm{Yb}_{0.4} \mathrm{Zr}_{2} \mathrm{O}_{7}$, $\mathrm{La}_{1.6} \mathrm{Lu}_{0.4} \mathrm{Zr}_{2} \mathrm{O}_{7}, \mathrm{La}_{2} \mathrm{Zr}_{1.6} \mathrm{Sn}_{0.4} \mathrm{O}_{7}$, etc. were presented. The sintered ceramics had low linear transmittance at $633 \mathrm{~nm}$ with a thickness of $0.4 \mathrm{~mm}$. As they have higher refractive indices than conventional glass and plastics, they might be used in optical devices. In 2008, The Schott Company also applied a US patent [99], in which $\mathrm{A}_{2+x} \mathrm{~B}_{y} \mathrm{D}_{z} \mathrm{E}_{7}$ series transparent ceramics were reported, like $\mathrm{Gd}_{2} \mathrm{Zr}_{2} \mathrm{O}_{7}$ and $\mathrm{Gd}_{2}(\mathrm{Hf}, \mathrm{Zr})_{2} \mathrm{O}_{7}$. The samples were firstly vacuum sintered at $1300{ }^{\circ} \mathrm{C}$ for $10 \mathrm{~h}$ with $10^{-5}-10^{-6}$ mbar vacuum degree, then HIPed at $1500{ }^{\circ} \mathrm{C}$ for $10 \mathrm{~h}$ with a pressure of $200 \mathrm{MPa}$. In the patent, other zirconates like $\mathrm{La}_{2} \mathrm{Zr}_{2} \mathrm{O}_{7}, \mathrm{Y}_{2} \mathrm{Zr}_{2} \mathrm{O}_{7}$, and $\mathrm{Yb}_{2} \mathrm{Zr}_{2} \mathrm{O}_{7}$, etc., were also mentioned, but no detailed fabrication information was given.

In 2011, An et al. [45] fabricated $\mathrm{La}_{2} \mathrm{Zr}_{2} \mathrm{O}_{7}$ transparent ceramic by reactive spark plasma sintering. The sintered body exhibited a pyrochlore structure and a uniform microstructure with the average grain size of $1.5 \mu \mathrm{m}$. The transmittance (Fig. 15) increased with increasing wavelength and reached $68 \%$ at $4-6 \mu \mathrm{m}$,

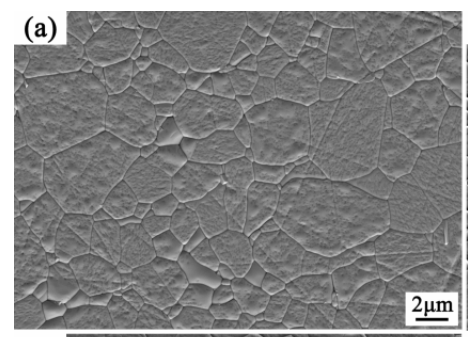

(d)
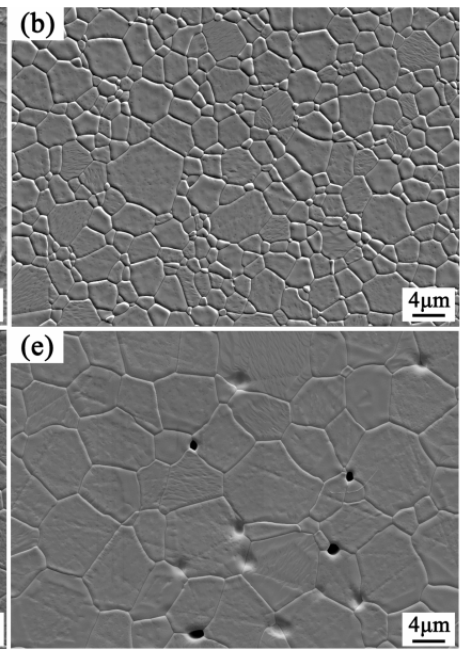
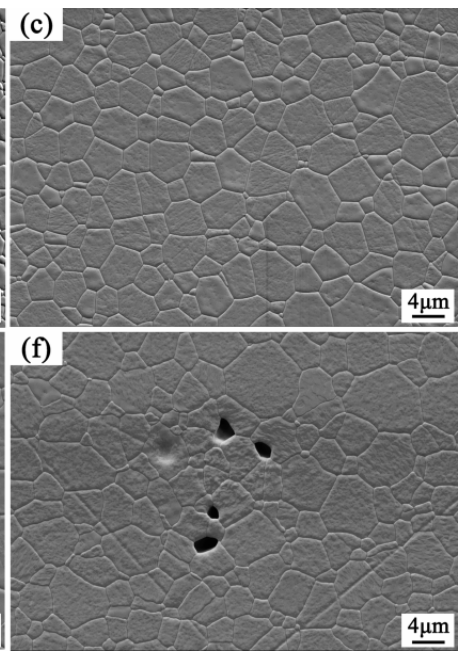

Fig. 13 Thermally etched surfaces of $\mathrm{La}_{2-x} \mathrm{Gd}_{x} \mathrm{Hf}_{2} \mathrm{O}_{7}$ transparent ceramics: (a) $x=0$; (b) $x=0.4$; (c) $x=0.8$; (d) $x=1.2$; (e) $x=$ 1.6; and (f) $x=2.0$. Reproduced with permission from Ref. [44], (C) Elsevier B.V. 2015. 

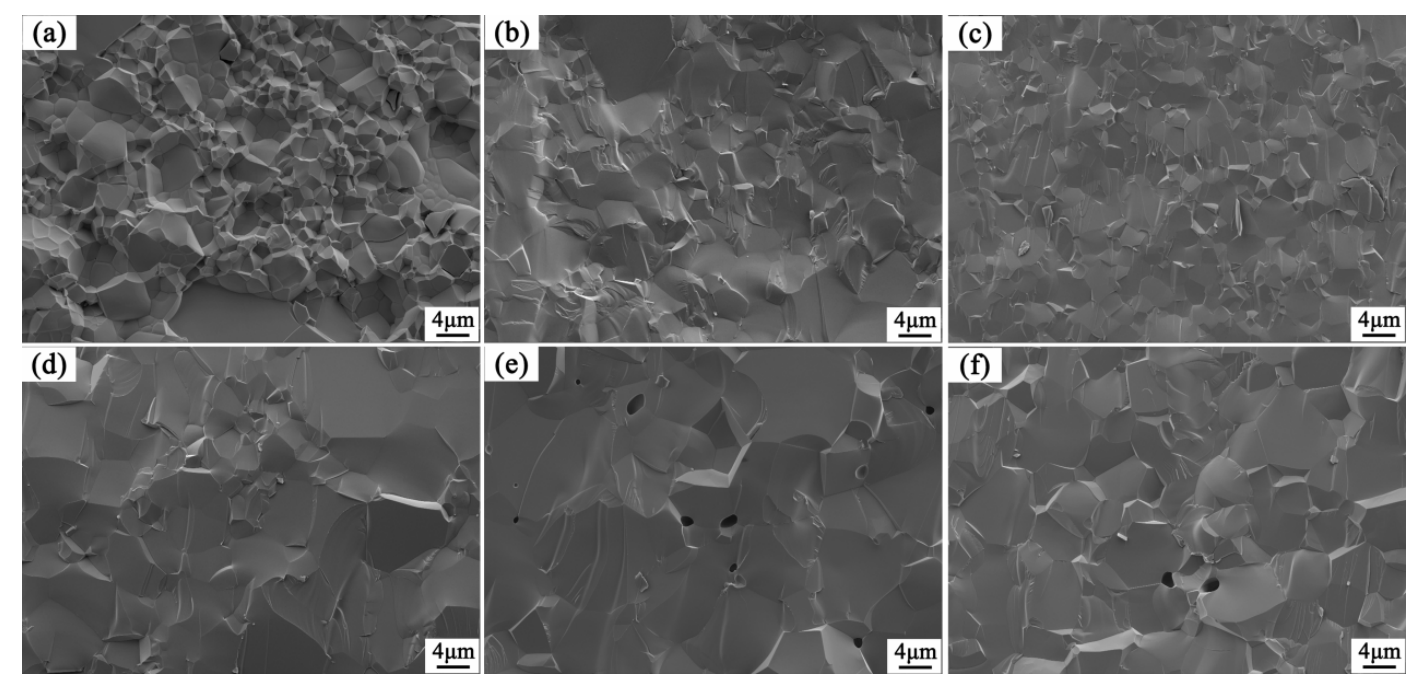

Fig. 14 Fracture surfaces of $\mathrm{La}_{2-x} \mathrm{Gd}_{x} \mathrm{Hf}_{2} \mathrm{O}_{7}$ transparent ceramics: (a) $x=0$; (b) $x=0.4$; (c) $x=0.8$; (d) $x=1.2$; (e) $x=1.6$; and (f) $x=2.0$. Reproduced with permission from Ref. [44], (c) Elsevier B.V. 2015.

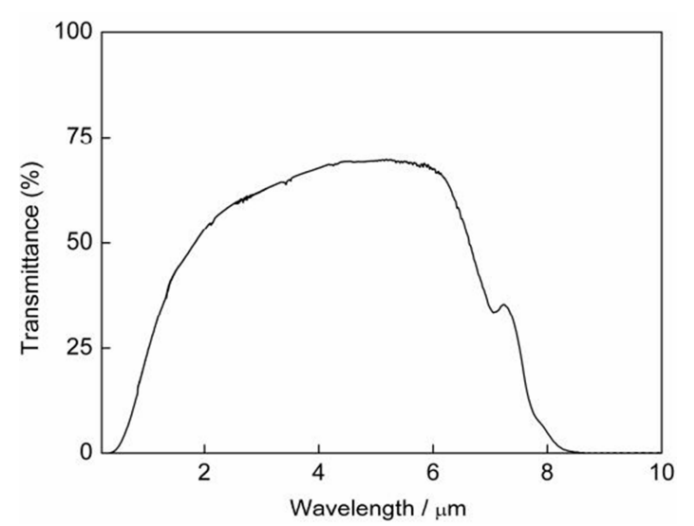

Fig. 15 Transmittance of $\mathrm{La}_{2} \mathrm{Zr}_{2} \mathrm{O}_{7}$ transparent ceramic sintered at $1400{ }^{\circ} \mathrm{C}$ for $45 \mathrm{~min}(1 \mathrm{~mm}$ thick). Reproduced with permission from Ref. [44], (C) Trans Tech Publications, Switzerland 2011.

while the absorption edge in the infrared range was 8.5 $\mu \mathrm{m}$. However, the transmittance in the visible range was relatively low. Zou et al. [83] fabricated $\mathrm{Y}_{2} \mathrm{Zr}_{2} \mathrm{O}_{7}$ transparent ceramic by vacuum sintering at $1850{ }^{\circ} \mathrm{C}$ for $6 \mathrm{~h}$ from combustion-synthesized powders. The as-burnt $\mathrm{Y}_{2} \mathrm{Zr}_{2} \mathrm{O}_{7}$ powders calcined at $1200{ }^{\circ} \mathrm{C}$ exhibited a defect fluorite structure and a porous morphology. The powders after being ball milled for $20 \mathrm{~h}$ can be sintered into transparent ceramics. The resultant ceramics show a pore-free microstructure and an in-line transmittance of $68 \%$ in the visible spectral region. On the other hand, Feng et al. [46] fabricated transparent $\mathrm{Nd}_{2} \mathrm{Zr}_{2} \mathrm{O}_{7}$ ceramics by sintering in $\mathrm{H}_{2}$ atmosphere at $1800{ }^{\circ} \mathrm{C}$ for $6-12 \mathrm{~h}$ using $\mathrm{Nd}_{2} \mathrm{Zr}_{2} \mathrm{O}_{7}$ nanoparticles synthesized by combustion method. Emission at $1054.5 \mathrm{~nm}$ has been demonstrated using a laser diode pump at $800 \mathrm{~nm}$, and the decay time is 460 $\mu \mathrm{s}$, making $\mathrm{Nd}_{2} \mathrm{Zr}_{2} \mathrm{O}_{7}$ transparent ceramic an excellent candidate for efficient high-power microchip lasers.

In 2013, Wang et al. [47,48] reported $\mathrm{La}_{2-x} \mathrm{Gd}_{x} \mathrm{Zr}_{2} \mathrm{O}_{7}$ transparent ceramics. $\mathrm{La}_{2-x} \mathrm{Gd}_{x} \mathrm{Zr}_{2} \mathrm{O}_{7}$ nanometric powders were synthesized by combustion method with glycine as the fuel. Then vacuum sintering was carried out to obtain the final transparent ceramics. With the increase of $\mathrm{Gd}^{3+}$ content, all the ceramics kept cubic pyrochlore structure, but the X-ray diffraction peaks shifted to higher angle as the lattice parameters became smaller. All the ceramics are transparent with high in-line transmittance and high refractive index (2.08@632.8 $\mathrm{nm}, x=0.4-1.6$ ), indicating that $\mathrm{La}_{2-x} \mathrm{Gd}_{x} \mathrm{Zr}_{2} \mathrm{O}_{7}$ ceramics might be used as optical lens. Moreover, with the increase of $\mathrm{Gd}^{3+}$ content, the effective atomic number and density of the ceramics increased, making them promising host candidates for scintillators. Then $\mathrm{Eu}^{3+}$ was chosen as the activator to study the luminescence properties of $\mathrm{La}_{2-x} \mathrm{Gd}_{x} \mathrm{Zr}_{2} \mathrm{O}_{7}: \mathrm{Eu}^{3+}$ transparent ceramics (Fig. 16) [53]. They found that the cubic pyrochlore structure was not changed with the doping of 3 at $\%$ $\mathrm{Eu}^{3+}$, while the cut-off edge of the transmittance curves and the luminescence behavior of the ceramics were affected by the annealing process as well as the Gd content. The cut-off edge shifted to opposite direction for the annealed and unannealed ceramics (Fig. 17). In addition, the luminescence intensity became stronger for the ceramics annealed in air. The doping of $\mathrm{Gd}^{3+}$ into $\mathrm{La}^{3+}$ site can change the energy band structure and the luminescence behavior was also adjusted. For ceramics annealed in air, the strongest luminescence 


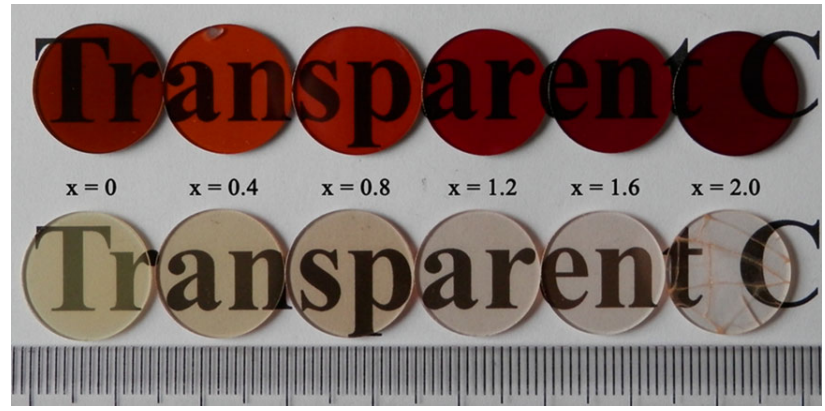

Fig. 16 Photograph of $\mathrm{La}_{1.94-x} \mathrm{Gd}_{x} \mathrm{Zr}_{2} \mathrm{O}_{7}: 3 \mathrm{at} \% \mathrm{Eu}^{3+}(x=$ 0-2.0) transparent ceramics before (above) and after (below) annealing. Reproduced with permission from Ref. [53], (C) John Wiley and Sons 2015.
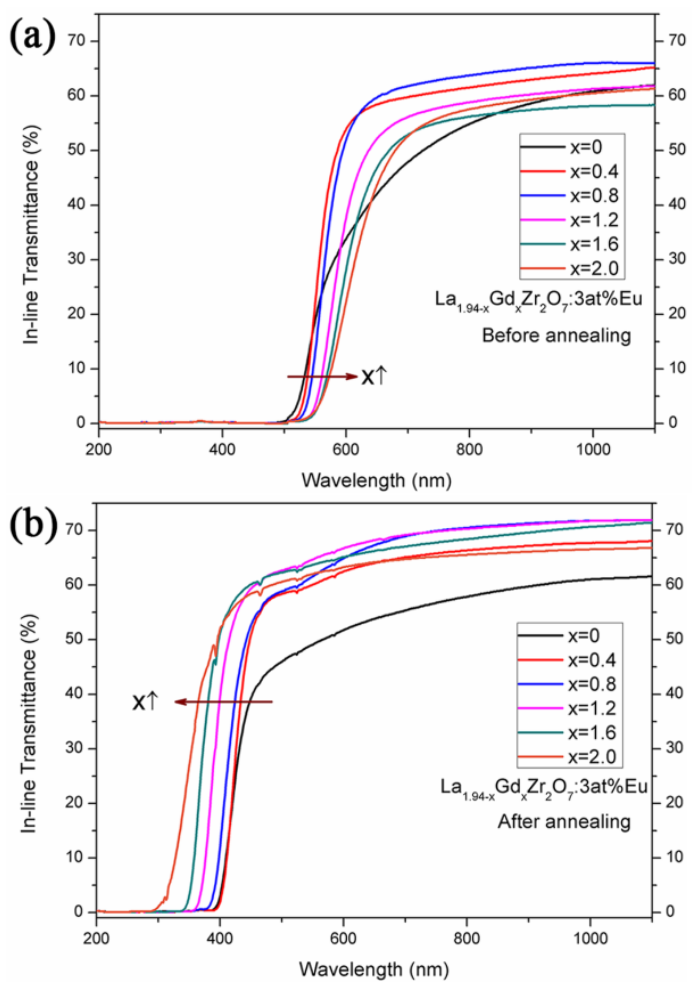

Fig. 17 Transmittance of $\mathrm{La}_{1.94-x} \mathrm{Gd}_{x} \mathrm{Zr}_{2} \mathrm{O}_{7}: 3 \mathrm{at} \% \mathrm{Eu}^{3+}$ $(x=0-2.0)$ transparent ceramics (a) before and (b) after annealing. Reproduced with permission from Ref. [53], (C) John Wiley and Sons 2015.

peaks changed from 585 to around $630 \mathrm{~nm}$ due to the reduction of the crystal symmetry.

Further, $\mathrm{LaYZr}_{2} \mathrm{O}_{7}$ and $\mathrm{La}_{2-x} \mathrm{Lu}_{x} \mathrm{Zr}_{2} \mathrm{O}_{7}$ transparent ceramics were prepared. Yi et al. [85] used slip casting to obtain the $\mathrm{LaYZr}_{2} \mathrm{O}_{7}$ green body and got $\mathrm{LaYZr}_{2} \mathrm{O}_{7}$ transparent ceramic by vacuum sintering at $1800{ }^{\circ} \mathrm{C}$ for $6 \mathrm{~h}$. The obtained transparent ceramic has high transparency with a transmittance of $76.5 \%$ at $1100 \mathrm{~nm}$, which was very close to the theoretical value (77.2\%). Wang et al. [49] prepared $\mathrm{La}_{2-x} \mathrm{Lu}_{x} \mathrm{Zr}_{2} \mathrm{O}_{7}$ transparent ceramics (Fig. 18) by solid state reactive sintering in vacuum. Surprisingly, with the increase of $\mathrm{Lu}$ content $(x)$, phase transition from pyrochlore to defective fluorite occurred and a two-phase region existed in the range of $x=0.6-1.2$ (Fig. 19). Grain sizes of the pyrochlore phase dominated samples $(x<0.5)$ were 11-14 $\mu \mathrm{m}$, and that of the defective fluorite phase dominated samples were larger than $60 \mu \mathrm{m}$. However, grain sizes of the samples in the two-phase region were smaller than $3 \mu \mathrm{m}$ (Fig. 20). The $\mathrm{La}_{0.8} \mathrm{Lu}_{1.2} \mathrm{Zr}_{2} \mathrm{O}_{7}$ ceramic with the smallest grain size $(\sim 2.5 \mu \mathrm{m})$ reached a highest in-line transmittance of $72.4 \%$ at $1100 \mathrm{~nm}$ among all the samples. According to Rayleigh-GansDebye scattering theory, when the refractive indices of the coexisting two phases are close to each other and the average grain size is smaller than $10 \mu \mathrm{m}$, the two phases have little influence on transparency of the ceramics.

\section{5. $3 \quad \mathrm{~A}_{2} \mathrm{Ti}_{2} \mathrm{O}_{7}$ system transparent ceramics}

Until now, research on $\mathrm{A}_{2} \mathrm{Ti}_{2} \mathrm{O}_{7}$ transparent ceramics was not much, and the potential application is focused on optoceramics and imaging optics (optical elements).

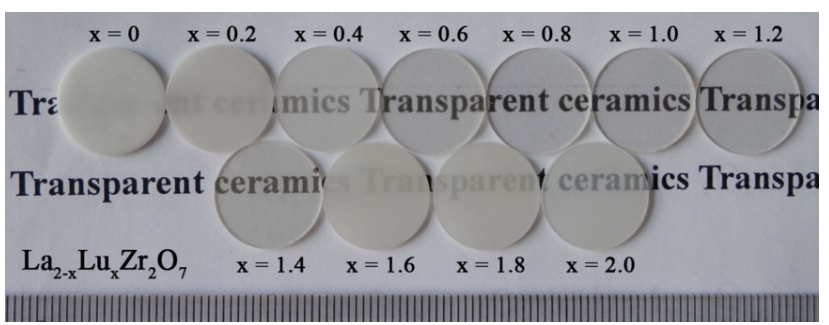

Fig. 18 Photograph of $\mathrm{La}_{2-x} \mathrm{Lu}_{x} \mathrm{Zr}_{2} \mathrm{O}_{7}(x=0-2.0)$ ceramics sintered at $1830{ }^{\circ} \mathrm{C}$ for $6 \mathrm{~h}$ in vacuum and annealed at $1500{ }^{\circ} \mathrm{C}$ for $5 \mathrm{~h}(1 \mathrm{~mm}$ thick $)$. Reproduced with permission from Ref. [49], (c) Elsevier Ltd. 2014.

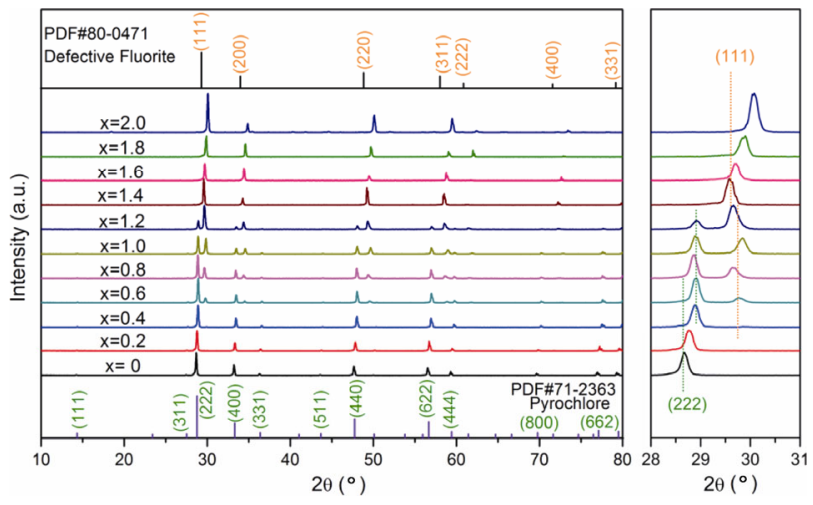

Fig. $19 \mathrm{XRD}$ patterns of $\mathrm{La}_{2-x} \mathrm{Lu}_{x} \mathrm{Zr}_{2} \mathrm{O}_{7}(x=0-2.0)$ ceramics. Reproduced with permission from Ref. [49], (C) Elsevier Ltd. 2014. 


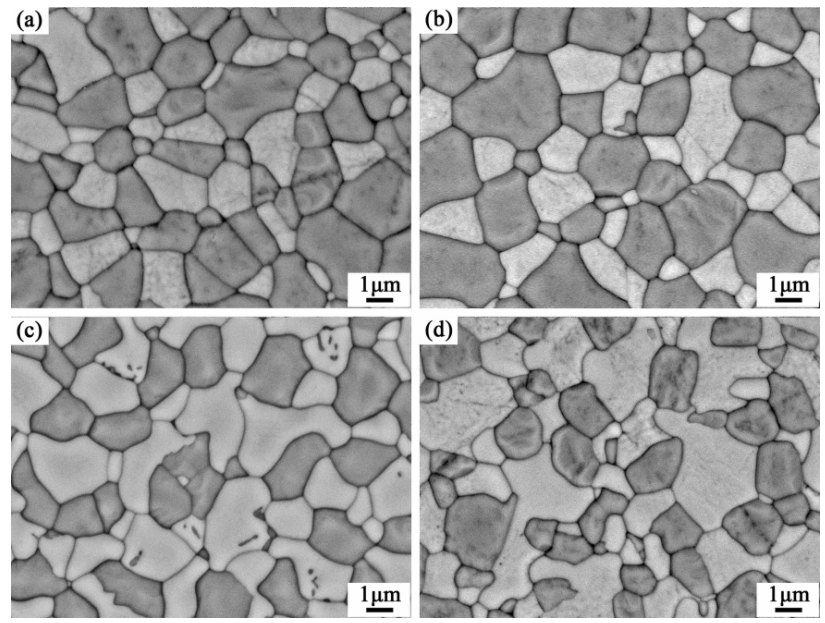

Fig. 20 Backscattered electron images of thermal-etched surfaces of $\mathrm{La}_{2-x} \mathrm{Lu}_{x} \mathrm{Zr}_{2} \mathrm{O}_{7}$ ceramics: (a) $x=0.6$, (b) $x=$ 0.8 , (c) $x=1.0$, and (d) $x=1.2$. Reproduced with permission from Ref. [49], (C) Elsevier Ltd. 2014.

As the melting temperature of $\mathrm{A}_{2} \mathrm{Ti}_{2} \mathrm{O}_{7}$ compounds was lower than that of $\mathrm{A}_{2} \mathrm{Hf}_{2} \mathrm{O}_{7}$ and $\mathrm{A}_{2} \mathrm{Zr}_{2} \mathrm{O}_{7}$, the fabrication of $\mathrm{A}_{2} \mathrm{Ti}_{2} \mathrm{O}_{7}$ transparent ceramics is expected to be easier with lower sintering temperature.

In 2008, The Schott Company applied a US patent [96] and reported $\mathrm{Y}_{2} \mathrm{Ti}_{2} \mathrm{O}_{7}, \mathrm{Yb}_{2} \mathrm{Ti}_{2} \mathrm{O}_{7}, \mathrm{Lu}_{2} \mathrm{Ti}_{2} \mathrm{O}_{7}$, and $\mathrm{Gd}_{2} \mathrm{Ti}_{2} \mathrm{O}_{7}$ transparent ceramics. However, the optical properties of these transparent ceramics were not given. Then in 2011, An et al. [50] prepared $\mathrm{Lu}_{2} \mathrm{Ti}_{2} \mathrm{O}_{7}$ transparent ceramic by spark plasma sintering. The sintered body exhibited $72 \%$ transmittance at a wavelength of $2000 \mathrm{~nm}$ and $40 \%$ transmittance at 550 $\mathrm{nm}$ (Fig. 21). The average grain size was $14.5 \mu \mathrm{m}$ with uniform microstructure. With cubic pyrochlore structure and high refractive index (2.57 at $632.8 \mathrm{~nm}$ ), $\mathrm{Lu}_{2} \mathrm{Ti}_{2} \mathrm{O}_{7}$ transparent ceramic is particularly suitable for application in an optical imaging system. Further work on improving the optical quality is needed. Moreover, other $\mathrm{A}_{2} \mathrm{Ti}_{2} \mathrm{O}_{7}$ system transparent ceramics would be developed to enrich the application fields. Recently, Wang et al. [102] found that the addition of excess $\mathrm{Y}$ can improve the transparency of $\mathrm{Y}_{2} \mathrm{Ti}_{2} \mathrm{O}_{7}$ transparent ceramics fabricated by solid state reactive sintering in vacuum. When the excess amount of Y to Ti is $2 \%$, the highest in-line transmittance reached to $49.9 \%$ at 1100 $\mathrm{nm}$ (Fig. 22). In their newly unpublished work, the transparency of $\mathrm{Y}_{2} \mathrm{Ti}_{2} \mathrm{O}_{7}$ transparent ceramic was greatly improved to $72.9 \%(0.5 \mathrm{~mm}$ thick $)$ at $1100 \mathrm{~nm}$ by using powders synthesized by co-precipitation method.
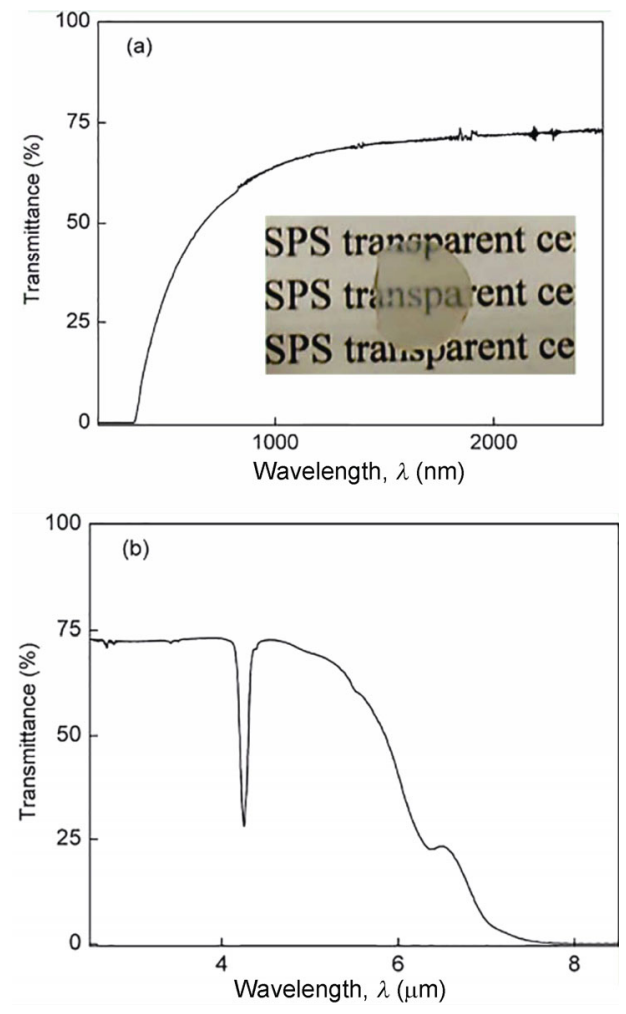

Fig. 21 Transmittance and photograph of $\mathrm{Lu}_{2} \mathrm{Ti}_{2} \mathrm{O}_{7}$ transparent ceramic $(0.8 \mathrm{~mm}$ thick). Reproduced with permission from Ref. [50], (C) Elsevier Ltd. 2010.

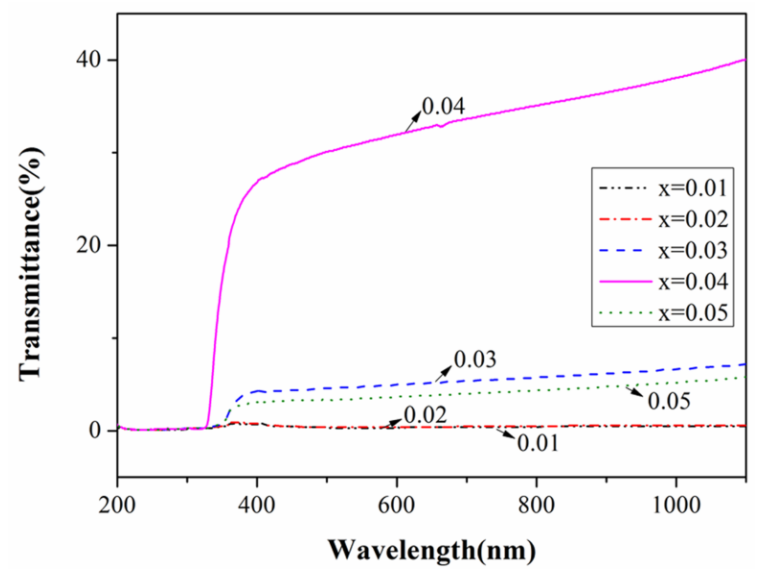

Fig. 22 Transmittance of $\mathrm{Y}_{2+x} \mathrm{Ti}_{2} \mathrm{O}_{7+3 x / 2}$ ceramics vacuum sintered at $1600{ }^{\circ} \mathrm{C}$ for $6 \mathrm{~h}$ and annealed at $1000{ }^{\circ} \mathrm{C}$ for $6 \mathrm{~h}(0.5 \mathrm{~mm}$ thick). Reproduced with permission from Ref. [102], (C) Elsevier Ltd. 2018.

\section{Potential applications}

As a new series of transparent ceramics, $\mathrm{A}_{2} \mathrm{~B}_{2} \mathrm{O}_{7}$ system transparent ceramics are promising in fields such as lasers, camera lens, bulletproof windows or missile radome, and scintillators. However, there are 
no practical applications up to now because the studies of $\mathrm{A}_{2} \mathrm{~B}_{2} \mathrm{O}_{7}$ system transparent ceramics are still in experimental stage.

The most potential application is scintillator, as most of the $\mathrm{A}_{2} \mathrm{~B}_{2} \mathrm{O}_{7}$ transparent ceramics have high density and high effective atomic number, which would gain high $\mathrm{X}$-ray or $\gamma$-ray stopping power. The density increased in the order of $\mathrm{A}_{2} \mathrm{Ti}_{2} \mathrm{O}_{7}, \mathrm{~A}_{2} \mathrm{Zr}_{2} \mathrm{O}_{7}$, and $\mathrm{A}_{2} \mathrm{Hf}_{2} \mathrm{O}_{7}$, and thus the $\mathrm{A}_{2} \mathrm{Hf}_{2} \mathrm{O}_{7}$ system transparent ceramics doping with proper rare earth ions are promising as a new series of transparent ceramic scintillators. However, the luminescence properties reported up to now were not attractive. On one hand, the luminescence intensity was not as high as the usual transparent ceramic scintillators. On the other hand, fast decay of $\mathrm{Ce}^{3+}$ and $\mathrm{Pr}^{3+}$ luminescence was not detected as expected in these ceramics. Chaudhry et al. [57] also came up with the idea that the Ce $5 \mathrm{~d}$ state lies above the CBM (conduction band minimum), which would prevent any luminescence from the $\mathrm{Ce}$ site. In the study of $\mathrm{La}_{2} \mathrm{Hf}_{2} \mathrm{O}_{7}: \operatorname{Pr}$ nanoceramics [42], no $5 \mathrm{~d} \rightarrow$ 4f photoluminescence emission was observed, which was also explained that the lowest $5 \mathrm{~d}$ level of $\mathrm{Pr}^{3+}$ was positioned within the conduction band of the host lattice. Only $\operatorname{Pr}^{3+} 4 f \rightarrow 4 f$ emission was observed means this type of transparent ceramic is promising to be used in X-ray excited scintillators.

Wang [56] studied the transmittance of $\mathrm{La}_{2-x} \mathrm{Gd}_{x} \mathrm{Zr}_{2} \mathrm{O}_{7}$ and $\mathrm{La}_{2-x} \mathrm{Gd}_{x} \mathrm{Hf}_{2} \mathrm{O}_{7}$ transparent ceramics in IR region, finding that the cut-off edges of the transmittance curve of these transparent ceramics were all larger than $8 \mu \mathrm{m}$. Compared with the IR cut-off edge of traditional transparent ceramics (AlON: $\sim 5.55 \mu \mathrm{m}$; YAG: $\sim 6.2 \mu \mathrm{m}$; $\left.\mathrm{Y}_{2} \mathrm{O}_{3}: \sim 9.4 \mu \mathrm{m} ; \mathrm{MgAl}_{2} \mathrm{O}_{4}: \sim 6.5 \mu \mathrm{m}\right)$, these two system transparent ceramics have relatively wider IR transmission range, thus they may be new candidates for IR windows. The tested flexural strength and Vickers hardness of $\mathrm{LaGdZr}_{2} \mathrm{O}_{7}$ transparent ceramics were about $194 \mathrm{MPa}$ and $10 \mathrm{GPa}$, which are higher than those of $\mathrm{Y}_{2} \mathrm{O}_{3}$ transparent ceramic. Except for excellent infrared optical properties, mechanical and thermal properties are also essential for IR window use, so further studies are needed.

In recent years, the increasing requirements from both sophisticated industrial as well as consumer mass markets have asked for optical transparent materials with extraordinary property combinations. For example, the continuous trend to miniaturization of digital photographic devices like digital cameras requires optical materials with very high refractive indices up to 2.0 or even higher, whereas industrial devices like optical microscopes require materials with special dispersion characteristics [6]. $\mathrm{A}_{2} \mathrm{~B}_{2} \mathrm{O}_{7}$ system transparent ceramics can be used as optical lens as they have high refractive index (higher than 2). The refractive index of $\mathrm{Y}_{2} \mathrm{Hf}_{2} \mathrm{O}_{7}, \quad \mathrm{La}_{2-x} \mathrm{Gd}_{x} \mathrm{Zr}_{2} \mathrm{O}_{7}$, and $\mathrm{Lu}_{2} \mathrm{Ti}_{2} \mathrm{O}_{7}$ was 2.018, 2.08, and 2.57, respectively. In 2012, Kintaka et al. [103] reported the optical properties of $\mathrm{La}_{2} \mathrm{Zr}_{2} \mathrm{O}_{7}$ transparent ceramic and its abnormal partial dispersion when performed for optical use. The origin of the abnormal partial dispersion was investigated by measuring the vacuum ultraviolet reflectance and infrared absorption and by performing first-principle calculations. As the $\mathrm{A}_{2} \mathrm{Ti}_{2} \mathrm{O}_{7}$ system have the highest refractive index among the $\mathrm{A}_{2} \mathrm{~B}_{2} \mathrm{O}_{7}$ system, more attentions would be paid on high refractive index optical elements applications of this kind of transparent ceramics.

In 2005, Gentleman and Clarke [104] found that $\mathrm{Eu}^{3+}$ doping into $\mathrm{Gd}_{2} \mathrm{Zr}_{2} \mathrm{O}_{7}$ can give rise to strong luminescence as well as characteristic temperaturedependent luminescence lifetime at high temperatures. So they proposed the $\mathrm{Eu}^{3+}$-doped materials could be employed in a number of different configurations for temperature sensing in thermal barrier coating systems. Recently, the luminescence properties of $\mathrm{Pr}^{3+}$-doped $\mathrm{La}_{0.4} \mathrm{Gd}_{1.6} \mathrm{Zr}_{2} \mathrm{O}_{7}$ transparent ceramics were studied and continuous change in intensity ratio between the emission around $610 \mathrm{~nm}$ and the other bands (our unpublished data). Such an effect is appreciated in temperature sensing by changes in luminescence. Thus, $\mathrm{A}_{2} \mathrm{~B}_{2} \mathrm{O}_{7}$ system transparent ceramics with rare-earth ion doping could be new candidates as non-contact temperature sensors, and further study is in progress.

\section{Conclusions and summary}

Since the first fabrication of $\mathrm{La}_{2} \mathrm{Hf}_{2} \mathrm{O}_{7}$ and $\mathrm{Gd}_{2} \mathrm{Hf}_{2} \mathrm{O}_{7}$ transparent ceramics appeared in $2005, \mathrm{~A}_{2} \mathrm{~B}_{2} \mathrm{O}_{7}$ system transparent ceramics such as $\mathrm{A}_{2} \mathrm{Hf}_{2} \mathrm{O}_{7}, \mathrm{~A}_{2} \mathrm{Zr}_{2} \mathrm{O}_{7}$, and $\mathrm{A}_{2} \mathrm{Ti}_{2} \mathrm{O}_{7}$ have been developed for scintillator hosts as most of them have high density and effective atomic number, which would gain higher X-ray or $\gamma$-ray stopping power. In this review, the structure characteristic, powder synthesis method, ceramic sintering method, the reported $\mathrm{A}_{2} \mathrm{Hf}_{2} \mathrm{O}_{7}, \mathrm{~A}_{2} \mathrm{Zr}_{2} \mathrm{O}_{7}$, and $\mathrm{A}_{2} \mathrm{Ti}_{2} \mathrm{O}_{7}$ system transparent ceramics, and the potential applications of 
$\mathrm{A}_{2} \mathrm{~B}_{2} \mathrm{O}_{7}$ system transparent ceramics were systematically summarized. In the near future, the applications on scintillators and optical elements would be focused continually, and newly developed applications such as temperature sensor, possible IR window, and optical lens would be further studied. The $\mathrm{A}_{2} \mathrm{Hf}_{2} \mathrm{O}_{7}$ system transparent ceramics would be paid more attention on scintillator applications for their high density and high effective number. As the raw material prices of $\mathrm{A}_{2} \mathrm{Zr}_{2} \mathrm{O}_{7}$ system transparent ceramics are relatively low, the researches on luminescence properties and the corresponding further application would be the key point. The $\mathrm{A}_{2} \mathrm{Ti}_{2} \mathrm{O}_{7}$ system transparent ceramics tend to be used as optical elements for their higher refractive indices. Further studies are needed, including the fabrication of $\mathrm{A}_{2} \mathrm{Ti}_{2} \mathrm{O}_{7}$ system transparent ceramics with optimized properties, including various refractive indices, Abbe numbers, and partial dispersions as well as high transmission and high property homogeneity.

\section{Acknowledgements}

The authors gratefully acknowledge the financial supports from the National Key R\&D Program of China (No. 2017YFB0310500) and the National Natural Science Foundation of China (No. 51602326).

\section{References}

[1] Coble RL. Transparent alumina and method of preparation. U.S. Patent 3,026,210. 1962.

[2] Fang Y, Agrawal D, Skandan G, et al. Fabrication of translucent $\mathrm{MgO}$ ceramics using nanopowders. Mater Lett 2004, 58: 551-554.

[3] Eilers H. Fabrication, optical transmittance, and hardness of IR-transparent ceramics made from nanophase yttria. $J$ Eur Ceram Soc 2007, 27: 4711-4717.

[4] Gupta TK, Rossing BR, Straub WD. Fabrication of transparent polycrystalline CaO. J Am Ceram Soc 1973, 56: 339-339.

[5] Kortov VS, Milman II, Slesarev AI, et al. New BeO ceramics for TL ESR dosimetry. Radiat Prot Dosim 1993, 47: 267-270.

[6] Peuchert U, Okano Y, Menke Y, et al. Transparent cubic- $\mathrm{ZrO}_{2}$ ceramics for application as optical lenses. J Eur Ceram Soc 2009, 29: 283-291.

[7] Tsukuma K. Transparent $\mathrm{MgAl}_{2} \mathrm{O}_{4}$ spinel ceramics produced by HIP post-sintering. J Ceram Soc Jpn 2006, 114: 802-806.

[8] Dutta S, Gazza G. Hot pressing ceramic oxides to transparency by heating in isothermal increments. U.S. Patent 3,767,745. 1973.

[9] Zeman HD, Dibianca FA, Lovhoiden G. High-resolution X-ray imaging with a $\mathrm{Gd}_{2} \mathrm{O}_{3}(\mathrm{Eu})$ transparent ceramic scintillator. In: Proc. SPIE 2432, Medical Imaging 1995: Physics of Medical Imaging, 1995: 454-461.

[10] Zou X, Yi H, Zhou G, et al. Highly transmitting $\mathrm{ZrO}_{2}$-doped $\mathrm{Lu}_{2} \mathrm{O}_{3}$ ceramics from combustion synthesized powders. J Am Ceram Soc 2011, 94: 2772-2774.

[11] Seeley ZM, Kuntz JD, Cherepy NJ, et al. Transparent $\mathrm{Lu}_{2} \mathrm{O}_{3}:$ Eu ceramics by sinter and HIP optimization. Opt Mater 2011, 33: 1721-1726.

[12] Qin X, Zhou G, Yang H, et al. Fabrication and plasma resistance properties of transparent YAG ceramics. Ceram Int 2012, 38: 2529-2535.

[13] Qin X, Yang H, Zhou G, et al. Fabrication and properties of highly transparent Er:YAG ceramics. Opt Mater 2012, 34: 973-976.

[14] Snow GS. Fabrication of transparent electrooptic PLZT ceramics by atmosphere sintering. J Am Ceram Soc 1973, 56: 91-96.

[15] Duclos SJ, Greskovich CD, Lyons RJ, et al. Development of the HiLight ${ }^{\mathrm{TM}}$ scintillator for computed tomography medical imaging. Nucl Instrum Meth A 2003, 505: 68-71.

[16] Riedner RJ, Gürmen EO, Greskovich CD, et al. Solid state scintillator and treatment therefor. U.S. Patent 4,783,596. 1988.

[17] Yamada H, Suzuki A, Uchida Y, et al. A scintillator $\mathrm{Gd}_{2} \mathrm{O}_{2} \mathrm{~S}: \mathrm{Pr}, \mathrm{Ce}, \mathrm{F}$ for X-ray computed tomography. $J$ Electrochem Soc 1989, 136: 2713-2716.

[18] Van Eijk CWE. Inorganic scintillators in medical imaging. Phys Med Biol 2002, 47: R85.

[19] Tsoukala VG, Greskovich CD. Hole-trap-compensated scintillator material. U.S. Patent 5,318,722. 1994.

[20] Lyberis A, Patriarche G, Gredin P, et al. Origin of light scattering in ytterbium doped calcium fluoride transparent ceramic for high power lasers. J Eur Ceram Soc 2011, 31: 1619-1630.

[21] Lin W-Y, Hon M-H, Yang S-J. Effect of grain growth on hot-pressed optical magnesium fluoride ceramics. $J \mathrm{Am}$ Ceram Soc 1988, 71: C-136-C-137.

[22] Basiev TT, Doroshenko ME, Fedorov PP, et al. Efficient laser based on $\mathrm{CaF}_{2}-\mathrm{SrF}_{2}-\mathrm{YbF}_{3}$ nanoceramics. Opt Lett 2008, 33: 521-523.

[23] Demidenko AA, Garibin EA, Gain SD, et al. Scintillation parameters of $\mathrm{BaF}_{2}$ and $\mathrm{BaF}_{2}: \mathrm{Ce}^{3+}$ ceramics. Opt Mater 2010, 32: 1291-1293.

[24] Kuramoto N, Taniguchi H. Transparent AlN ceramics. $J$ Mater Sci Lett 1984, 3: 471-474.

[25] Chen F, Zhang F, Wang J, et al. Microstructure and optical properties of transparent aluminum oxynitride ceramics by hot isostatic pressing. Scripta Mater 2014, 81: 20-23.

[26] Wang J, Zhang F, Chen F, et al. Fabrication of aluminum oxynitride $(\gamma$-AlON) transparent ceramics with modified gelcasting. J Am Ceram Soc 2014, 97: 1353-1355. 
[27] Mandal H. New developments in $\alpha$-SiAlON ceramics. $J$ Eur Ceram Soc 1999, 19: 2349-2357.

[28] Chlique C, Merdrignac-Conanec O, Hakmeh N, et al. Transparent $\mathrm{ZnS}$ ceramics by sintering of high purity monodisperse nanopowders. J Am Ceram Soc 2013, 96: 3070-3074.

[29] Colomban P, Havel M. Raman imaging of stress-induced phase transformation in transparent $\mathrm{ZnSe}$ ceramic and sapphire single crystals. J Raman Spectrosc 2002, 33: 789-795.

[30] Kolesnikov NN, Kveder VV, Borisenko EB, et al. Structure and properties of $\mathrm{CdTe}$ ceramics produced through nanopowder compaction. J Cryst Growth 2005, 285: 339-344.

[31] Fu-k'ang F, Kuznetsov AK, Keler ÉK. Zirconates of the rare earth elements and their physicochemical properties. Report 1. Zirconates of lanthanum, neodymium and cerium. Russ Chem Bull 1964, 13: 1070-1075.

[32] Clarke DR, Phillpot SR. Thermal barrier coating materials. Mater Today 2005, 8: 22-29.

[33] Zhang A, Lü M, Yang Z, et al. Systematic research on $\mathrm{RE}_{2} \mathrm{Zr}_{2} \mathrm{O}_{7}(\mathrm{RE}=\mathrm{La}, \mathrm{Nd}, \mathrm{Eu}$ and $\mathrm{Y})$ nanocrystals: Preparation, structure and photoluminescence characterization. Solid State Sci 2008, 10: 74-81.

[34] Trojan-Piegza J, Zych E, Kosinska M. Fabrication and spectroscopic properties of nanocrystalline $\mathrm{La}_{2} \mathrm{Hf}_{2} \mathrm{O}_{7}: \mathrm{Pr}$. Radiat Meas 2010, 45: 432-434.

[35] Eberman KW, Wuensch BJ, Jorgensen JD. Order-disorder transformations induced by composition and temperature change in $\left(\mathrm{Sc}_{z} \mathrm{Yb}_{1-z}\right)_{2} \mathrm{Ti}_{2} \mathrm{O}_{7}$ pyrochlores, prospective fuel cell materials. Solid State Ionics 2002, 148: 521-526.

[36] Kim N, Grey CP. ${ }^{17} \mathrm{O}$ MAS NMR study of the oxygen local environments in the anionic conductors $\mathrm{Y}_{2}\left(B_{1-x} B^{\prime}{ }_{x}\right)_{2} \mathrm{O}_{7}(B$, $\left.B^{\prime}=\mathrm{Sn}, \mathrm{Ti}, \mathrm{Zr}\right)$. J Solid State Chem 2003, 175: 110-115.

[37] Uno M, Kosuga A, Okui M, et al. Photoelectrochemical study of lanthanide zirconium oxides, $\mathrm{Ln}_{2} \mathrm{Zr}_{2} \mathrm{O}_{7}(\mathrm{Ln}=\mathrm{La}$, Ce, Nd and Sm). J Alloys Compd 2006, 420: 291-297.

[38] Yokoi H, Arita Y, Matsui T, et al. EXAFS study of $\left(\mathrm{La}_{1-x} \mathrm{M}_{x}\right)_{2} \mathrm{Zr}_{2} \mathrm{O}_{7}(\mathrm{M}=\mathrm{Nd}$ and Ce). $J$ Nucl Mater 1996, 238: 163-168.

[39] Ewing RC. Nuclear waste disposal-pyrochlore $\left(\mathrm{A}_{2} \mathrm{~B}_{2} \mathrm{O}_{7}\right)$ : Nuclear waste form for the immobilization of plutonium and "minor" actinides. $J$ Appl Phys 2004, 95: 5949-5971.

[40] Whittle KR, Cranswick LMD, Redfern SA, et al. Lanthanum pyrochlores and the effect of yttrium addition in the systems $\mathrm{La}_{2-x} \mathrm{Y}_{x} \mathrm{Zr}_{2} \mathrm{O}_{7}$ and $\mathrm{La}_{2-x} \mathrm{Y}_{x} \mathrm{Hf}_{2} \mathrm{O}_{7} . J$ Solid State Chem 2009, 182: 442-450.

[41] Ji Y, Jiang D, Fen T, et al. Fabrication of transparent $\mathrm{La}_{2} \mathrm{Hf}_{2} \mathrm{O}_{7}$ ceramics from combustion synthesized powders. Mater Res Bull 2005, 40: 553-559.

[42] Trojan-Piegza J, Gierlotka S, Zych E, et al. Spectroscopic studies of nanopowder and nanoceramics $\mathrm{La}_{2} \mathrm{Hf}_{2} \mathrm{O}_{7}: \mathrm{Pr}$ scintillator. J Am Ceram Soc 2014, 97: 1595-1601.

[43] Yi H, Zou X, Yang Y, et al. Fabrication of highly transmitting $\mathrm{LaGdHf}_{2} \mathrm{O}_{7}$ ceramics. J Am Ceram Soc 2011,
94: 4120-4122.

[44] Wang Z, Zhou GH, Zhang F, et al. Fabrication and properties of $\mathrm{La}_{2-x} \mathrm{Gd}_{x} \mathrm{Hf}_{2} \mathrm{O}_{7}$ transparent ceramics. J Lumin 2016, 169: 612-615.

[45] An L, Ito A, Goto T. Fabrication of transparent $\mathrm{La}_{2} \mathrm{Zr}_{2} \mathrm{O}_{7}$ by reactive spark plasma sintering. Key Eng Mater 2011, 484: 135-138.

[46] Feng T, Clarke DR, Jiang D, et al. Neodymium zirconate $\left(\mathrm{Nd}_{2} \mathrm{Zr}_{2} \mathrm{O}_{7}\right)$ transparent ceramics as a solid state laser material. Appl Phys Lett 2011, 98: 151105.

[47] Wang Z, Zhou G, Qin X, et al. Fabrication of $\mathrm{LaGdZr}_{2} \mathrm{O}_{7}$ transparent ceramic. J Eur Ceram Soc 2013, 33: 643-646.

[48] Wang Z, Zhou G, Qin X, et al. Transparent $\mathrm{La}_{2-x} \mathrm{Gd}_{x} \mathrm{Zr}_{2} \mathrm{O}_{7}$ ceramics obtained by combustion method and vacuum sintering. J Alloys Compd 2014, 585: 497-502.

[49] Wang Z, Zhou G, Qin XP, et al. Fabrication and phase transition of $\mathrm{La}_{2-x} \mathrm{Lu}_{x} \mathrm{Zr}_{2} \mathrm{O}_{7}$ transparent ceramics. $J$ Eur Ceram Soc 2014, 34: 3951-3958.

[50] An L, Ito A, Goto T. Highly transparent lutetium titanium oxide produced by spark plasma sintering. J Eur Ceram Soc 2011, 31: 237-240.

[51] Ji Y, Jiang D, Shi J. Preparation and spectroscopic properties of $\mathrm{La}_{2} \mathrm{Hf}_{2} \mathrm{O}_{7}: \mathrm{Tb}$. Mater Lett 2005, 59: 868-871.

[52] Ji Y, Jiang D, Shi J. $\mathrm{La}_{2} \mathrm{Hf}_{2} \mathrm{O}_{7}: \mathrm{Ti}^{4+}$ ceramic scintillator for $\mathrm{X}$-ray imaging. J Mater Res 2005, 20: 567-570.

[53] Wang Z, Zhou G, Zhang J, et al. Effect of Gd content on luminescence properties of $\mathrm{Eu}^{3+}$-doped $\mathrm{La}_{2-x} \mathrm{Gd}_{x} \mathrm{Zr}_{2} \mathrm{O}_{7}$ transparent ceramics. J Am Ceram Soc 2015, 98: 2476 2479.

[54] Wang Z, Zhou G, Zhang J, et al. Luminescence properties of $\mathrm{Eu}^{3+}$-doped lanthanum gadolinium hafnates transparent ceramics. Opt Mater 2017, 71: 5-8.

[55] Subramanian MA, Aravamudan G, Subba Rao GV. Oxide pyrochlores-A review. Prog Solid State Chem 1983, 15: 55-143.

[56] Wang ZJ. Fabrication and properties of $\mathrm{Ln}_{2} \mathrm{M}_{2} \mathrm{O}_{7}(\mathrm{M}=\mathrm{Zr}$, Hf) transparent ceramics. Ph.D. Thesis. Beijing, China: University of Chinese Academy of Sciences, 2015.

[57] Chaudhry A, Canning A, Boutchko R, et al. First-principles studies of Ce-doped $\mathrm{RE}_{2} \mathrm{M}_{2} \mathrm{O}_{7}(\mathrm{RE}=\mathrm{Y}, \mathrm{La} ; \mathrm{M}=\mathrm{Ti}, \mathrm{Zr}, \mathrm{Hf})$ : A class of non-scintillators. J Appl Phys 2011, 109: 083708 .

[58] Shimamura K, Arima T, Idemitsu K, et al. Thermophysical properties of rare-earth-stabilized zirconia and zirconate pyrochlores as surrogates for actinide-doped zirconia. Int $J$ Thermophys 2007, 28: 1074-1084.

[59] Blanchard PER, Clements R, Kennedy BJ, et al. Does local disorder occur in the pyrochlore zirconates? Inorg Chem 2012, 51: 13237-13244.

[60] Hayashi T. Translucent ceramic, method for producing the same, optical component, and optical device. U.S. Patent $0,233,406.2008$

[61] Mandal BP, Garg N, Sharma SM, et al. Preparation, XRD and Raman spectroscopic studies on new compounds $R E_{2} \mathrm{Hf}_{2} \mathrm{O}_{7}(R E=\mathrm{Dy}, \mathrm{Ho}, \mathrm{Er}, \mathrm{Tm}, \mathrm{Lu}, \mathrm{Y})$ : Pyrochlores or defect-fluorite? J Solid State Chem 2006, 179: 1990-1994. 
[62] Moreno KJ, Rodrigo RS, Fuentes AF. Direct synthesis of $\mathrm{A}_{2}\left(\mathrm{Ti}_{(1-y)} \mathrm{Zr}_{y}\right)_{2} \mathrm{O}_{7}\left(\mathrm{~A}=\mathrm{Gd}^{3+}, \mathrm{Y}^{3+}\right)$ solid solutions by ball milling constituent oxides. J Alloys Compd 2005, 390: 230-235.

[63] Moreno KJ, Fuentes AF, Garcia-Barriocanal J, et al. Mechanochemical synthesis and ionic conductivity in the $\mathrm{Gd}_{2}\left(\mathrm{Sn}_{1-y} \mathrm{Zr}_{y}\right)_{2} \mathrm{O}_{7}(0 \leq y \leq 1)$ solid solution. J Solid State Chem 2006, 179: 323-330.

[64] Jin D, Yu X, Yang H, et al. Hydrothermal synthesis and luminescence properties of $\mathrm{Yb}^{3+}$ doped rare earth stannates. J Alloys Compd 2009, 474: 557-560.

[65] Gao L, An Y, Zhu H, et al. Hydrothermal synthesis and photoluminescence properties of $\mathrm{Y}_{2} \mathrm{Zr}_{2} \mathrm{O}_{7}: \mathrm{Tb}^{3+}$ phosphors. J Mater Sci 2011, 46: 1337-1340.

[66] Pavitra E, Seeta Rama Raju G, Yu JS. Solvothermal synthesis and luminescent properties of $\mathrm{Y}_{2} \mathrm{Ti}_{2} \mathrm{O}_{7}: \mathrm{Eu}^{3+}$ spheres. Phys Status Solidi RRL 2013, 7: 224-227.

[67] Mao Y, Park T-J, Zhang F, et al. Environmentally friendly methodologies of nanostructure synthesis. Small 2007, 3: 1122-1139.

[68] Mao Y, Guo X, Huang JY, et al. Luminescent nanocrystals with $\mathrm{A}_{2} \mathrm{~B}_{2} \mathrm{O}_{7}$ composition synthesized by a kinetically modified molten salt method. $J$ Phys Chem C 2009, 113: 1204-1208.

[69] Shlyakhtina AV, Shcherbakova LG, Knotko AV. Studies of new order-disorder structural transitions in $\mathrm{Ln}_{2} \mathrm{M}_{2} \mathrm{O}_{7}(\mathrm{Ln}=$ Lu, Gd; M = Ti). Ferroelectrics 2003, 294: 175-190.

[70] Shlyakhtina AV, Shcherbakova LG, Knotko AV, et al. Study of the fluorite-pyrochlore-fluorite phase transitions in $\mathrm{Ln}_{2} \mathrm{Ti}_{2} \mathrm{O}_{7}(\mathrm{Ln}=\mathrm{Lu}, \mathrm{Yb}, \mathrm{Tm}) . J$ Solid State Electrochem 2004, 8: 661-667.

[71] Wan CL, Pan W, Xu Q, et al. Effect of point defects on the thermal transport properties of $\left(\mathrm{La}_{x} \mathrm{Gd}_{1-x}\right)_{2} \mathrm{Zr}_{2} \mathrm{O}_{7}$ : Experiment and theoretical model. Phys Rev B 2006, 74 : 144109.

[72] Liu Z-G, Ouyang J-H, Zhou Y. Preparation and thermophysical properties of $\left(\mathrm{Nd}_{x} \mathrm{Gd}_{1-x}\right){ }_{2} \mathrm{Zr}_{2} \mathrm{O}_{7}$ ceramics. $J$ Mater Sci 2008, 43: 3596-3603.

[73] Zhou B-Z, Zhou G-H, An L-Q, et al. Morphologycontrolled synthesis of yttrium hafnate by oxalate co-precipitation method and the growth mechanism. $J$ Alloys Compd 2009, 481: 434-437.

[74] LaCourse BC, Hardy AB, Rétot HL, et al. Ceramic scintillator body and scintillation device. U.S. Patent 0012787. 2012.

[75] Kido H, Komarneni S, Roy R. Preparation of $\mathrm{La}_{2} \mathrm{Zr}_{2} \mathrm{O}_{7}$ by sol-gel route. J Am Ceram Soc 1991, 74: 422-424.

[76] Li X, Cai H, Ding L, et al. Synthesis and luminescence properties of $\mathrm{La}_{2} \mathrm{Ti}_{2} \mathrm{O}_{7}: \mathrm{Er}^{3+}$ nanocrystals with pyrochlore structure. J Alloys Compd 2012, 541: 36-40.

[77] Saif M, Shebl M, Mbarek A, et al. Synthesis of non-toxic phosphor material based on pyrochlore-type dititanate $\left(\mathrm{Eu}^{3+} / \mathrm{Y}_{2} \mathrm{Ti}_{2} \mathrm{O}_{7}\right)$. J Photochem Photobiol A 2015, 301: 1-5.

[78] Tong Y, Xue P, Jian F, et al. Preparation and characterization of $\mathrm{Y}_{2} \mathrm{Zr}_{2} \mathrm{O}_{7}$ nanocrystals and their photocatalytic properties. Mat Sci Eng B 2008, 150: 194-198.

[79] Dhas NA, Patil KC. Combustion synthesis and properties of fine-particle rare-earth-metal zirconates, $\mathrm{Ln}_{2} \mathrm{Zr}_{2} \mathrm{O}_{7} . J$ Mater Chem 1993, 3: 1289-1294.

[80] Liao Y, Jiang D, Ji YM, et al. Combustion synthesis of nanosized $\mathrm{Y}_{2} \mathrm{Hf}_{2} \mathrm{O}_{7}$ and $\mathrm{Lu}_{2} \mathrm{Hf}_{2} \mathrm{O}_{7}$ powders. Key Eng Mater 2005, 280-283: 643-646.

[81] Zhang A, Lü M, Zhou G, et al. Combustion synthesis and photoluminescence of $\mathrm{Eu}^{3+}, \mathrm{Dy}^{3+}$-doped $\mathrm{La}_{2} \mathrm{Zr}_{2} \mathrm{O}_{7}$ nanocrystals. J Phys Chem Solids 2006, 67: 2430-2434.

[82] Orlovskaya N, Chen Y, Miller N, et al. Glycine-nitrate synthesis of $\mathrm{Sr}$ doped $\mathrm{La}_{2} \mathrm{Zr}_{2} \mathrm{O}_{7}$ pyrochlore powder. $A d v$ Appl Ceram 2011, 110: 54-57.

[83] Zou X, Zhou G, Yi H, et al. Fabrication of transparent $\mathrm{Y}_{2} \mathrm{Zr}_{2} \mathrm{O}_{7}$ ceramics from combustion-synthesized powders. $J$ Am Ceram Soc 2011, 94: 1002-1004.

[84] Wang Z, Zhou G, Qin X, et al. Two-phase $\mathrm{LaLuZr}_{2} \mathrm{O}_{7}$ transparent ceramic with high transparency. $J$ Am Ceram Soc 2014, 97: 2035-2037.

[85] Yi H, Wang Z, Zhou G, et al. Highly transparent $\mathrm{LaYZr}_{2} \mathrm{O}_{7}$ ceramic fabricated by slip casting. Ceram Int 2016, 42: 2070-2073.

[86] Zou X-Q, Zhou G-H, Yi H-L, et al. Fabrication of transparent $\mathrm{Y}_{2} \mathrm{Hf}_{2} \mathrm{O}_{7}$ ceramic from combustion synthesized powders. J Inorg Mater 2011, 26: 929-932.

[87] Zhou G, Wang Z, Zhou B, et al. Fabrication of transparent $\mathrm{Y}_{2} \mathrm{Hf}_{2} \mathrm{O}_{7}$ ceramics via vacuum sintering. Opt Mater 2013, 35: 774-777.

[88] Wang SF, Zhang J, Luo DW, et al. Transparent ceramics: Processing, materials and applications. Prog Solid State Chem 2013, 41: 20-54.

[89] Ji YM. Exploration and luminescence properties of hafnate ceramic scintillators. Ph.D. Thesis. Shanghai Institute of Ceramics, Chinese Academy of Sciences, 2006.

[90] Zou XQ. Fabrication and luminescence properties of $\mathrm{RE}_{2} \mathrm{Hf}_{2} \mathrm{O}_{7} / \mathrm{RE}_{2} \mathrm{Zr}_{2} \mathrm{O}_{7}$ transparent ceramics. Master Thesis. Shanghai Institute of Ceramics, Chinese Academy of Sciences, 2011.

[91] Anselmi-Tamburini U, Woolman JN, Munir ZA. Transparent nanometric cubic and tetragonal zirconia obtained by high-pressure pulsed electric current sintering. Adv Funct Mater 2007, 17: 3267-3273.

[92] Galusek D, Sedláček J, Chovanec J, et al. The influence of $\mathrm{MgO}, \mathrm{Y}_{2} \mathrm{O}_{3}$ and $\mathrm{ZrO}_{2}$ additions on densification and grain growth of submicrometre alumina sintered by SPS and HIP. Ceram Int 2015, 41: 9692-9700.

[93] Reimanis I, Kleebe H-J. A review on the sintering and microstructure development of transparent spinel $\left(\mathrm{MgAl}_{2} \mathrm{O}_{4}\right)$. J Am Ceram Soc 2009, 92: 1472-1480.

[94] Gan L, Park Y-J, Kim H, et al. Fabrication of submicrongrained IR-transparent $\mathrm{Y}_{2} \mathrm{O}_{3}$ ceramics from commercial nano-raw powders. Ceram Int 2015, 41: 11992-11998.

[95] Serivalsatit K, Ballato J. Submicrometer grain-sized transparent erbium-doped scandia ceramics. J Am Ceram 
Soc 2010, 93: 3657-3662.

[96] Peuchert U, Menke Y. Optoceramics, optical elements manufactured thereof and their use as well as imaging optics. U.S. Patent 7,710,656. 2010.

[97] Lu TC, Chang XH, Qi JQ, et al. Low-temperature high-pressure preparation of transparent nanocrystalline $\mathrm{MgAl}_{2} \mathrm{O}_{4}$ ceramics. Appl Phys Lett 2006, 88: 213120.

[98] Hreniak D, Bettinelli M, Speghini A, et al. The $\mathrm{f}-\mathrm{f}$ emission of $\mathrm{Pr}^{3+}$ ion as an optical probe for the structural properties of YAG nanoceramics. J Nanosci Nanotechnol 2009, 9: 6315-6319.

[99] Peuchert U, Menke Y. Active optoceramics with cubic crystal structure, method of production of the optoceramics, and uses thereof. U.S. Patent 8,197,711. 2012.

[100] Borisevich A, Korzhik M, Lecoq P. Luminescence of Ce doped oxygen crystalline compounds based on $\mathrm{Hf}$ and $\mathrm{Ba}$. Nucl Instrum Meth A 2003, 497: 206-209.

[101] Birxner LH. Structural and luminescent properties of the $\mathrm{Ln}_{2} \mathrm{Hf}_{2} \mathrm{O}_{7}$-type rare earth hafnates. Mat Res Bull 1984, 19:
143-149.

[102] Wang X, Xie J, Wang Z, et al. Fabrication and properties of $\mathrm{Y}_{2} \mathrm{Ti}_{2} \mathrm{O}_{7}$ transparent ceramics with excess $\mathrm{Y}$ content. Ceram Int 2018, 44: 9514-9518.

[103] Kintaka Y, Hayashi T, Honda A, et al. Abnormal partial dispersion in pyrochlore lanthanum zirconate transparent ceramics. J Am Ceram Soc 2012, 95: 2899-2905.

[104] Gentleman MM, Clarke DR. Luminescence sensing of temperature in pyrochlore zirconate materials for thermal barrier coatings. Surf Coat Technol 2005, 200: 1264-1269.

Open Access The articles published in this journal are distributed under the terms of the Creative Commons Attribution 4.0 International License (http://creativecommons.org/licenses/by/4.0/), which permits unrestricted use, distribution, and reproduction in any medium, provided you give appropriate credit to the original author(s) and the source, provide a link to the Creative Commons license, and indicate if changes were made. 